\title{
Biogenic iron oxyhydroxide formation at mid-ocean ridge hydrothermal vents: Juan de Fuca Ridge
}

\author{
Brandy M. Toner ${ }^{\mathrm{a}, *}$, Cara M. Santelli ${ }^{\mathrm{a}}$, Matthew A. Marcus ${ }^{\mathrm{b}}$, Richard Wirth ${ }^{\mathrm{c}}$, \\ Clara S. Chan ${ }^{\mathrm{a}}$, Thomas McCollom ${ }^{\mathrm{d}}$, Wolfgang Bach ${ }^{\mathrm{a}, \mathrm{e}}$, Katrina J. Edwards ${ }^{\mathrm{a}, \mathrm{f}, \mathrm{g}}$ \\ ${ }^{a}$ Department of Marine Chemistry and Geochemistry, Woods Hole Oceanographic Institution, Woods Hole, MA, USA \\ ${ }^{\mathrm{b}}$ The Advanced Light Source, Lawrence Berkeley National Laboratory, Berkeley, CA, USA \\ ${ }^{\mathrm{c}}$ GeoForschungsZentrum Potsdam, Potsdam, Germany \\ ${ }^{\mathrm{d}}$ University of Colorado at Boulder, Laboratory for Atmospheric and Space Physics, Boulder, CO, USA \\ ${ }^{\mathrm{e}}$ Fachbereich Geowissenschaften, Universität Bremen, Bremen, Germany \\ ${ }^{\mathrm{f}}$ Geomicrobiology Group, Department of Biological Sciences, University of Southern California, Los Angeles, CA, USA \\ ${ }^{\mathrm{g}}$ Department of Earth Sciences, University of Southern California, Los Angeles, CA, USA
}

Received 22 May 2008; accepted in revised form 19 September 2008

\begin{abstract}
Here we examine Fe speciation within Fe-encrusted biofilms formed during 2-month seafloor incubations of sulfide mineral assemblages at the Main Endeavor Segment of the Juan de Fuca Ridge. The biofilms were distributed heterogeneously across the surface of the incubated sulfide and composed primarily of particles with a twisted stalk morphology resembling those produced by some aerobic Fe-oxidizing microorganisms. Our objectives were to determine the form of biofilm-associated Fe, and identify the sulfide minerals associated with microbial growth. We used micro-focused synchrotron-radiation X-ray fluorescence mapping $(\mu \mathrm{XRF}), \mathrm{X}$-ray absorption spectroscopy ( $\mu \mathrm{EXAFS})$, and X-ray diffraction $(\mu \mathrm{XRD})$ in conjunction with focused ion beam (FIB) sectioning, and high resolution transmission electron microscopy (HRTEM). The chemical and mineralogical composition of an Fe-encrusted biofilm was queried at different spatial scales, and the spatial relationship between primary sulfide and secondary oxyhydroxide minerals was resolved. The Fe-encrusted biofilms formed preferentially at pyrrhotite-rich $\left(\mathrm{Fe}_{1-x} \mathrm{~S}\right.$, $0 \leqslant x \leqslant 0.2$ ) regions of the incubated chimney sulfide. At the nanometer spatial scale, particles within the biofilm exhibiting lattice fringing and diffraction patterns consistent with 2-line ferrihydrite were identified infrequently. At the micron spatial scale, Fe $\mu$ EXAFS spectroscopy and $\mu$ XRD measurements indicate that the dominant form of biofilm Fe is a short-range ordered Fe oxyhydroxide characterized by pervasive edge-sharing $\mathrm{Fe}-\mathrm{O}_{6}$ octahedral linkages. Double corner-sharing $\mathrm{Fe}-\mathrm{O}_{6}$ linkages, which are common to $\mathrm{Fe}$ oxyhydroxide mineral structures of 2-line ferrihydrite, 6-line ferrihydrite, and goethite, were not detected in the biogenic iron oxyhydroxide (BIO). The suspended development of the BIO mineral structure is consistent with Fe(III) hydrolysis and polymerization in the presence of high concentrations of Fe-complexing ligands. We hypothesize that microbiologically produced Fe-complexing ligands may play critical roles in both the delivery of $\mathrm{Fe}$ (II) to oxidases, and the limited Fe(III) oxyhydroxide crystallinity observed within the biofilm. Our research provides insight into the structure and formation of naturally occurring, microbiologically produced Fe oxyhydroxide minerals in the deep-sea. We describe the initiation of microbial seafloor weathering, and the morphological and mineralogical signals that result from that process. Our observations provide a starting point from which progressively older and more extensively weathered seafloor sulfide minerals may be examined, with the ultimate goal of improved interpretation of ancient microbial processes and associated biological signatures.
\end{abstract}




\section{INTRODUCTION}

Iron in a reduced chemical state, $\mathrm{Fe}(\mathrm{II})$, is dissolved in mid-ocean ridge (MOR) hydrothermal end-member fluids at concentrations ranging from 0.007 to $25 \mathrm{mmol} \mathrm{kg}^{-1}$ (German and von Damm, 2004). As vented hydrothermal fluids mix with cold, oxygenated deep-sea water, Fe-bearing sulfide minerals - along with $\mathrm{Zn}$ and $\mathrm{Cu}$ sulfides-precipitate, forming chimney structures at the seafloor and particles in hydrothermal plumes (Feely et al., 1987). The chemical and physical conditions present in the immediate vicinity of hydrothermal venting create strong gradients in temperature, concentration, and oxidation-reduction conditions over short length-scales (Tivey, 1995). A variety of energetically favorable chemical reactions can occur spontaneously, or be catalyzed by microorganisms that are responsible for primary productivity in vent ecosystems (Karl et al., 1980; McCollom and Shock, 1997; Bach et al., 2006). The presence of microbial life in association with deep-sea hydrothermal venting has been documented in hydrothermal fluids (Huber et al., 2007; Perner et al., 2007), sediments ( Teske et al., 2002; Nercessian et al., 2005; Glynn et al., 2006), actively venting chimneys (Schrenk et al., 2003; Kormas et al., 2006), and extinct chimneys and sulfide mounds (Rogers et al., 2003; Suzuki et al., 2004; Blumenberg et al., 2007). Thermodynamic modeling of deep-sea hydrothermal vent chemistry indicates that the potential metabolic energy stored in precipitated phases may be greater than that of dissolved constituents; with oxidation of elemental sulfur and metal sulfides each representing approximately $600 \mathrm{cal} \mathrm{kg}^{-1}$ vent fluid (McCollom, 2000). The mechanisms by which deep-sea microbial communities use the chemical energy stored in sulfide minerals are poorly constrained and have become the topic of much focused research (Edwards et al., 2005).

At the Juan de Fuca Ridge, the role of deep-sea microbial communities in sulfide mineral alteration processes has been assessed through seafloor mineral incubation studies (Edwards et al., 2003a). These mineral incubations provide a time-constrained view of microbial colonization of sulfide minerals and the production of secondary minerals by native seafloor microorganisms. Edwards et al. (2003a) report that after 2 months at the seafloor, sulfide mineral surfaces were colonized at densities of $7-50 \times 10^{4}$ cells per $\mathrm{mm}^{2}$. In addition, colonization density was positively correlated with the solubility of sulfide minerals (i.e. pyrrhotite $>$ pyrite) and porosity of the sulfide aggregates. On the most heavily colonized material, a polished chip of natural chimney sulfide from the Juan de Fuca Ridge, accumulations of $\mathrm{Fe}$ - and O-rich particles with distinctly microbiological morphologies, such as twisted stalks, formed over and within pore spaces (Edwards et al., 2003a). Select particles within the Fe-encrusted biofilm were found to yield electron diffraction patterns corresponding to the Fe oxyhydroxide mineral 2-line ferrihydrite. The particles of twisted stalk morphology did not yield well-defined electron diffraction patterns and mineralogical information was not obtained. Because the chimney sample contained a mixture of sulfide minerals, and the Fe-encrusted microbial biofilms were scraped from the mineral surface prior to examination by transmission electron microscopy (TEM), the exact sulfide minerals present in associated with microbial colonization could not be determined.

In the present research, we reexamine subsamples of the same incubated sulfide minerals considered by Edwards et al. (2003a) in order to examine Fe speciation within the biofilm (composed of cells, extracellular structures, and mineral particles) and resolve the spatial relationship between primary sulfide minerals and secondary oxyhydroxide minerals. The goals of this research are to: (1) determine the form and speciation of $\mathrm{Fe}$ produced by microbiological weathering of seafloor sulfide minerals, and (2) identify the minerals that may be supporting microbiological activity. Synchrotron-radiation micro-focused X-ray fluorescence mapping ( $\mu \mathrm{XRF}), \mathrm{X}$-ray absorption spectroscopy ( $\mu \mathrm{XAS})$, and $\mathrm{X}$-ray diffraction $(\mu \mathrm{XRD})$ were used in conjunction with focused ion beam (FIB) sectioning, and HRTEM to query repeatedly the same $50 \times 150 \mu \mathrm{m}$ area of Fe-encrusted biofilm. This approach was essential to our research because: (1) the Fe-encrusted biofilms of interest were thin (usually $\leqslant 150 \mu \mathrm{m}$ ) and distributed heterogeneously across the surface of the incubated sulfide mineral, (2) bulk measurements of Fe speciation within the biofilm would be swamped out by the large Fe sulfide signal of the remaining substrates, and (3) visualization of the physical association between the primary and secondary minerals assists us in interpreting the mechanisms behind our observations.

\section{METHODS}

\subsection{Sample incubation and preparation}

The sample analyzed here is a replicate of those examined by Edwards et al. (2003a). A schematic representation of sample preparation and processing in this study is presented in Fig. 1. A polished thick section of a Juan de Fuca chimney sulfide (collected from the seafloor on a previous Alvin dive 3468-5) was mounted on a glass slide, cut into square chips $(1 \times 1 \times 0.3 \mathrm{~cm}$, referred to as a "chip"), and incubated at the seafloor for 2 months along with other pure metal sulfides (Edwards et al., 2003a). The incubation baskets (Fig. EA-1) were placed adjacent to the Hulk hydrothermal vent along the Endeavor segment of the ridge, away from the direct path of hydrothermal plumes. After retrieval from the seafloor (9/2000), the incubated chimney sulfide chips used for mineralogy were stored at $-80{ }^{\circ} \mathrm{C}$ without preservatives until shipment to Spectrum Petrographics, Inc. (6/2005). The incubated mineral chip was embedded in epoxy, sectioned, and polished. The sectioning of the incubated chip produced a glass slidemounted, $30 \mu \mathrm{m}$ thick, petrographic section that provided a depth-profile view of the interface between the primary sulfide minerals and the Fe-encrusted biofilm (Fig. 1B).

\subsection{Electron microscopy}

The scanning electron microscopy (SEM) images - of an incubated Juan de Fuca chimney chip - displayed in Figs. 1A and 3A were obtained on a JEOL 840 SEM (Marine Biological Laboratory's Microscopy facility) with $15 \mathrm{keV}$ 


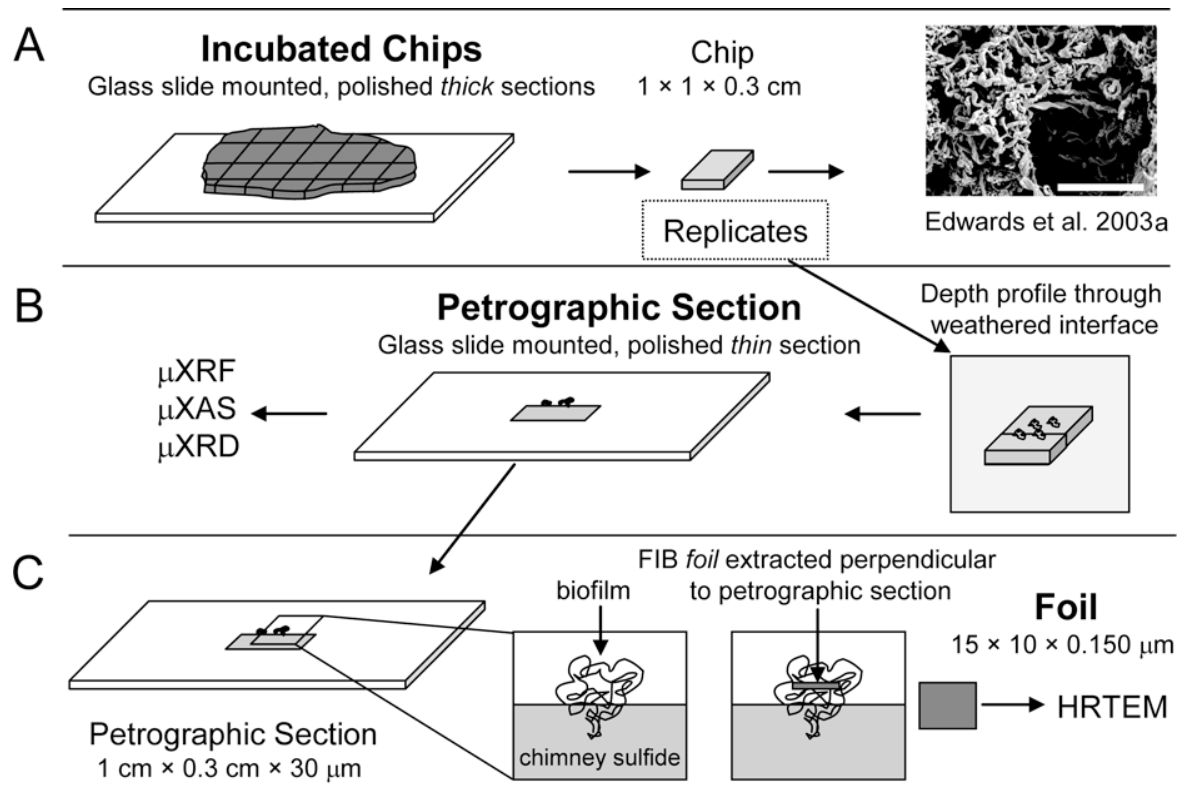

Fig. 1. Schematic of sample processing and analyses. (A) A natural Juan de Fuca chimney sulfide was attached to a standard glass microscope slide, polished, and cut into chips of approximately $1 \times 1 \times 0.3 \mathrm{~cm}(w \times d \times h)$ prior to incubation at the seafloor. Incubated chips were analyzed by scanning electron microscopy (SEM, scale bar $10 \mu \mathrm{m}$ ) and epi-fluorescent microscopy after staining DNA with fluorescent probes (Edwards et al., 2003a). (B) Petrographic sections displaying a weathering depth-profile were prepared from replicate incubated chips. Microfocused synchrotron-radiation X-ray fluorescence ( $\mu$ XRF), X-ray absorption spectroscopy ( $\mu$ XAS), and X-ray diffraction ( $\mu$ XRD) were performed on the petrographic section. (C) A transmission electron microscopy (TEM) foil was excised from the biofilm, perpendicular to the petrographic section, with focused ion beam (FIB) sectioning.

accelerating voltage after gold-palladium sputter coating (Edwards et al., 2003a).

Electron transparent foils were prepared with focused ion beam (FIB) sectioning (FEI FIB200 TEM; Postdam, Germany) from selected areas within the petrographic section (Fig. 1B and C). Specifically, the foils examined were obtained from within the Fe-encrusted biofilm only, and are not transects through the biofilm and into the sulfides. The foils were milled normal to the surface of the petrographic section after the deposition of a $1 \mu \mathrm{m}$ deep strip of Pt (Figs. 1C and 2A). The foils were approximately $15 \times 10 \times 0.150 \mu \mathrm{m}$ in size. The details of the FIB method are given elsewhere (Wirth, 2004). Briefly, the milling process begins with two large troughs milled from either side of the foil with high ion current $(2700 \mathrm{pA})$. The second stage of milling is conducted at lower current, $350 \mathrm{pA}$, to a foil thickness of approximately $500 \mathrm{~nm}$. The final polishing of the foil is conducted at $70 \mathrm{pA}$ at a low incident angle (i.e. nearly parallel to the foil).

TEM investigations were performed with a TECNAI F20 XTWIN TEM operating at $200 \mathrm{kV}$ with a field emission gun electron source (Potsdam, Germany). The TEM is equipped with a Gatan Tridiem ${ }^{\mathrm{TM}}$ filter, an EDX Genesis $^{\mathrm{TM}} \mathrm{X}$-ray analyzer with ultra thin window and a Fishione high angle annular dark field detector. The Tridiem filter was used for the acquisition of energy-filtered images applying a $20-\mathrm{eV}$ window to the zero loss peak. Energy dispersive $\mathrm{X}$-ray (EDX) spectra were acquired in the scanning transmission mode (STEM) using the TIA $^{\mathrm{TM}}$ software package of the TEM. Significant mass loss during analysis was avoided by scanning the beam in a pre-selected window (according to the size of the measured volume). Spot size was approximately $1 \mathrm{~nm}$, and acquisition time $60 \mathrm{~s}$.

\subsection{X-ray diffraction}

Two-dimensional, spatially resolved X-ray diffraction patterns were collected from the glass slide-mounted petrographic section at the Advanced Light Source on beamline 7.3.3 (Tamura et al., 2002). The specific sample areas of interest for XRD data collection were identified with Xray fluorescence (XRF) mapping. The XRD patterns were collected with a CCD camera in reflection mode with $6.3 \mathrm{keV}$ incident energy and $15 \times 8.5 \mu \mathrm{m}$ spot size at the sample. The two-dimensional diffraction patterns were processed with beamline 7.3.3 custom software to extract the intensity versus $d$-spacing plot displayed here.

\subsection{X-ray absorption spectroscopy}

$\mathrm{X}$-ray fluorescence (XRF) elemental maps and spatially resolved X-ray absorption spectra ( $\mu$ XAS) were collected at the Advanced Light Source on beamline 10.3.2 with a 7 -element germanium detector in fluorescence mode with a pixel size of $10 \times 10 \mu \mathrm{m}$ and a $16 \times 7 \mu \mathrm{m}$ beam spot (Marcus et al., 2004). XRF maps collected at high (13 keV) and low $(6.64 \mathrm{keV})$ energy were deadtime corrected and registered using custom beamline software. Based on the information provided by the XRF elemental maps, regions of interest were chosen for collection of Fe K-edge XAS data. The monochromator energy calibration was set with Fe foil at $7110.75 \mathrm{eV}$. The spectra were collected to a reciprocal 

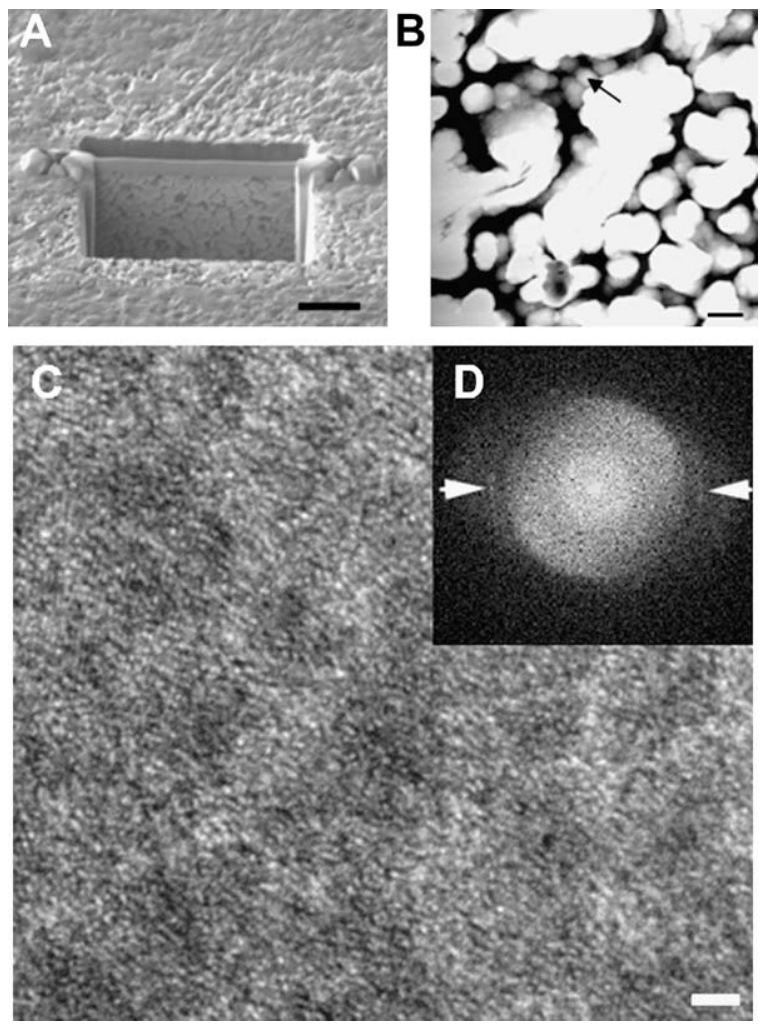

Fig. 2. (A) An SEM image of the location where a focused ion beam (FIB) foil was excavated from the polished petrographic section (scale bar $5 \mu \mathrm{m}$ ). (B) A scanning transmission electron microscope (STEM) image of a large subsection of the FIB foil collected with a high angle annular dark field (HAADF) detector (scale bar $500 \mathrm{~nm}$, full image of foil Fig. EA-3). The arrow indicates the location where HRTEM was conducted. (C) HRTEM image with scale bar $2 \mathrm{~nm}$. (D) Fourier transform of image shown in panel (C) exhibiting diffuse rings and weak spots (arrows) and indicating randomly oriented nanometer-scale crystals.

space $(k)$ value of $14.4\left(\AA^{-1}\right)$. Individual scans collected at the same location were examined for changes in line-shape and peak position, and no beam damage was observed. Experimental spectra were deadtime corrected, energy calibrated, and averaged. The spectra were compared to reference spectra collected from $\mathrm{Fe}$ oxyhydroxide minerals: goethite $(\alpha-\mathrm{FeOOH}), 6$-line ferrihydrite, and 2-line ferrihydrite. The synthesis and characterization of these reference materials is described elsewhere (Hansel et al., 2003).

Spectra in the $k$-range of $2-13.8\left(\AA^{-1}\right)$ were Fourier transformed, FT $\left[\begin{array}{ll}\chi(k) & k^{3}\end{array}\right]$, and fit using SixPack software (Webb, 2005) over specific $R$-ranges with phase and amplitude functions calculated with FEFF6 (Rehr et al., 1992). The crystal structure of goethite (Gualtieri and Venturelli, 1999) was used, with the program TkAtoms (Ravel, 1999), to generate the source information for the FEFF path calculations. The quality of each spectral fit was evaluated quantitatively with the reduced chi square $\left(\chi_{v}{ }^{2}\right)$ and $R$-factor parameters. The $R$-factor parameter represents the goodness of fit in terms of the point-by-point difference between the data and fit (Ravel, 2000): $R=\Sigma\left\{\left[\operatorname{Im}\left(\chi_{\text {dat }}\left(R_{\mathrm{i}}\right)-\chi_{\mathrm{th}}\left(R_{\mathrm{i}}\right)\right)\right]^{2}+\left[\operatorname{Re}\left(\chi_{\text {dat }}\left(R_{\mathrm{i}}\right)-\chi_{\mathrm{th}}\left(R_{\mathrm{i}}\right)\right)\right]^{2}\right\} /$
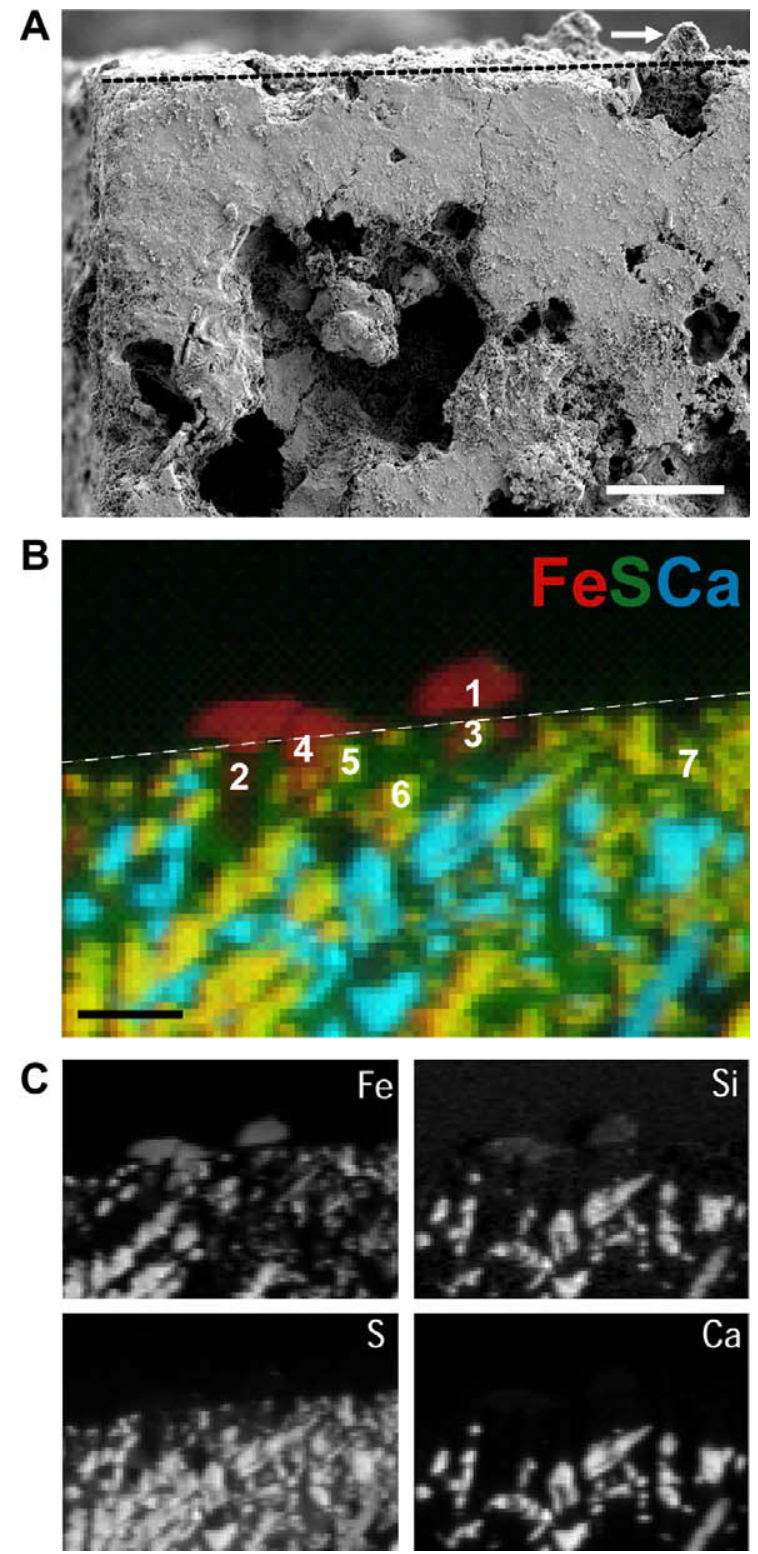

Fig. 3. A depth-profile view of the seafloor-incubated chip. (A) An SEM image of an incubated chip (Edwards et al., 2003a) (scale bar $100 \mu \mathrm{m})$. The arrow highlights an Fe-encrusted biofilm that formed after 2 months at the seafloor. The black dashed line shows the original chip surface. A replicate incubated chip was sectioned to produce a petrographic section. (B) The depth-profile displayed in (B) is an X-ray fluorescence (XRF) tricolor map of the petrographic section with $\mathrm{Fe}$ in red, $\mathrm{S}$ in green, and $\mathrm{Ca}$ in blue. The scale bar is $130 \mu \mathrm{m}$ and numbers represent locations of X-ray diffraction (spots 1-7) and XAS (spot 1) data collection. (C) Gray scale maps of individual elements are also displayed for $\mathrm{Fe}, \mathrm{Si}, \mathrm{S}$, and $\mathrm{Ca}$.

$\left\{\left[\operatorname{Im}\left(\chi_{\text {dat }}\left(R_{\mathrm{i}}\right)\right]^{2}+\left[\operatorname{Re}\left(\chi_{\text {dat }}\left(R_{\mathrm{i}}\right)\right]^{2}\right\}\right.\right.$, where $\operatorname{Im}\left(\chi_{\text {dat }}\left(R_{\mathrm{i}}\right)\right)$ and $\operatorname{Im}\left(\chi_{\mathrm{th}}\left(R_{\mathrm{i}}\right)\right)$ are the imaginary part, and $\operatorname{Re}\left(\chi_{\mathrm{dat}}\left(R_{\mathrm{i}}\right)\right)$ and $\operatorname{Re}\left(\chi_{\mathrm{th}}\left(R_{\mathrm{i}}\right)\right)$ the real part of the complex Fourier transformed data $\left(\chi_{\text {dat }}\right)$ and fit $\left(\chi_{\text {th }}\right)$. All fit parameters [interatomic distance, $R(\AA)$; coordination number, $N$; and mean-square displacement of bond length, $\left.\sigma^{2}\left(\AA^{2}\right)\right]$ are presented with the estimated errors from IFEFFIT calculations (Newville, 2001). A single value for the change in 
threshold energy, $\Delta E_{0}$, was obtained for each multi-shell fit. The amplitude reduction factor $\left(S_{0}{ }^{2}\right)$ for goethite was determined by constraining the number of first shell oxygen atoms, $N(\mathrm{Fe}-\mathrm{O})$, to a value of six, and was then held constant during fitting. The amplitude reduction factor $\left(S_{0}{ }^{2}\right)$ for the goethite fit was 0.58 . To put this parameter into context, $S_{0}^{2}$ for other Fe-bearing minerals are: pyrite $(0.45)$, marcasite (0.88), FeS (0.80), goethite (0.77), 2-line ferrihydrite $(0.70)$, illite $(0.76)$, nontronite $(0.76)$, and smectite (0.88) (O'Day et al., 2004). The relatively low value for our goethite may reflect a certain degree of over-absorption distortion in the spectrum (Manceau et al., 2002). Multiple scattering paths were not considered in the shell-by-shell fits. Third and fourth cumulants were included in $\mathrm{Fe}-\mathrm{Fe}$ second shell fitting of the experimental Fe EXAFS spectrum. These parameters did not improve the agreement between the fit and the data. The results of the cumulant expansion fitting are summarized in Fig. EA-2 and Table EA-1. A detailed description of micro-focused XRF, XRD, and XAS data collection and processing at the Advanced Light Source, Lawrence Berkeley National Laboratory is available (Manceau et al., 2002).

\section{RESULTS}

\subsection{Focused ion beam (FIB) sectioning and high resolution transmission electron microscopy (HRTEM)}

A glass slide-mounted, depth-profile view of the interface between the primary sulfide minerals and the Fe-encrusted biofilm was prepared as a petrographic section (Fig. 1B). Focused ion beam sectioning was performed on the petrographic section, perpendicular to the section, within an Fe-encrusted biofilm (Fig. 2A). A scanning transmission electron microscope (STEM) image of a portion of the FIB foil acquired with a high angle annular dark field (HAADF) detector is displayed in Fig. 2B. The FIB section shows an $\mathrm{Fe}$ - and O-rich material that is composed of round and elongated material with diameters and widths of approximately $0.5-1 \mu \mathrm{m}$ (Figs. EA-3-EA-5). At higher magnification, in the STEM imaging mode, we observed that the sphere-like structures are porous and composed of nanoparticles less than $10 \mathrm{~nm}$ in diameter (Fig. EA-6). The Fe- and O-rich material infrequently exhibited lattice fringes in high resolution images: a HRTEM image with lattice fringing is displayed in Fig. 2C. In some locations, HRTEM images reveal discrete particles of less than $5 \mathrm{~nm}$ in diameter separated by spaces of lower electron density (Fig. 2C), which confirms the observations of the STEM image acquired with the HAADF detector (Fig. EA-6). In the instances where lattice fringes were observed, diffraction patterns with $d$-spacings of $2.60,2.14$, and $1.56 \AA$ and broad scattering intensity were recorded.

\subsection{Micron-scale X-ray fluorescence mapping and X-ray diffraction}

\subsubsection{X-ray fluorescence ( $\mu X R F)$}

The distribution of $\mathrm{Fe}, \mathrm{S}$, and $\mathrm{Ca}$ within the Fe-encrusted biofilm and seafloor-incubated chimney sulfide chip is displayed in Fig. 3 (analysis performed on petrographic section). In this tricolor map, each pixel is colored with an amount of red proportional to the Fe counts, green proportional to $\mathrm{S}$ counts, and blue proportional to Ca counts in additive color combination. Thus, yellow (red plus green) pixels represent locations rich in $\mathrm{Fe}$ and $\mathrm{S}$, such as pyrrhotite $\left(\mathrm{Fe}_{1-x} \mathrm{~S}, 0 \leqslant x \leqslant 0.2\right)$ and cyan represents areas rich in $\mathrm{Ca}$ and $\mathrm{S}$ (anhydrite, $\mathrm{CaSO}_{4}$ ). The XRF mapping allows for selection of physically discrete and chemically unique areas of interest from which to collect X-ray absorption spectra. In this case, the primary areas of interest are those that are enriched in $\mathrm{Fe}$ and depleted in $\mathrm{S}$ - these are the products of sulfide mineral weathering.

The dashed line across the top of the tricolor XRF map in Fig. 3B corresponds to the polished surface of the chimney sulfide mineral chip prior to incubation on the seafloor. In this image, the Fe-enriched and S-depleted products of weathering can be seen as red, oval features that extend above the original surface. These weathering features also extend into the polished surface of the chimney sulfide. Gray scale elemental maps of the incubated chimney sulfide chip indicate that the Fe-encrusted biofilm is enriched slightly in Si relative to the sulfide minerals present in the chimney (Fig. 3C, Si panel). The Si-rich mineral grains within the sulfide chimney assemblage are anhydrite. The XRD and Fe XAS data collected do not support the presence of silicate minerals in general or Fe-bearing silicate minerals in particular. The tools used here would not distinguish between low concentration amorphous silica and $\mathrm{Fe}$ oxyhydroxide sorbed silica. Although the sulfide minerals of this incubated chimney sulfide also contain $\mathrm{Cu}$ and $\mathrm{Zn}$ sulfides, no enrichment of these elements was detectable in the biogenic Fe-rich products of weathering.

\subsection{2. $X$-ray diffraction ( $X R D)$}

Spatially resolved XRD patterns were collected at sample locations numbered 1-7 on the tricolor XRF map (Fig. 3B). The diffraction patterns, displayed in Fig. 4 and labeled 1-7, are arranged in order of crystallinity as defined by X-ray diffraction. The Fe-encrusted biofilm materials do not exhibit any well-defined XRD peaks; the only diffraction feature observed is a very broad, very weak band centered approximately at $2.6 \AA$. The areas of transition between the Fe-rich secondary minerals and the primary sulfide minerals is marked by the appearance of diffraction peaks corresponding to the sulfide mineral pyrrhotite with peaks visible at $1.44,1.60,1.72,2.06,2.64$, and $2.98 \AA$ (Fig. 4).

\subsection{Spatially resolved extended $X$-ray absorption fine structure ( $\mu \mathrm{EXAFS})$ spectroscopy}

\subsubsection{Goethite and a polyhedral approach to iron oxyhydroxide structure}

The use of EXAFS spectroscopy for characterization of Fe oxyhydroxide mineral structures hinges on detection of interatomic distances indicative of specific linkages between $\mathrm{Fe}-\mathrm{O}_{6}$ polyhedra: for example, corner-, edge-, and facesharing octahedra (Manceau and Combes, 1988; Combes et al., 1989). In Fig. 5A, the $k^{3}$-weighted Fe EXAFS spec- 


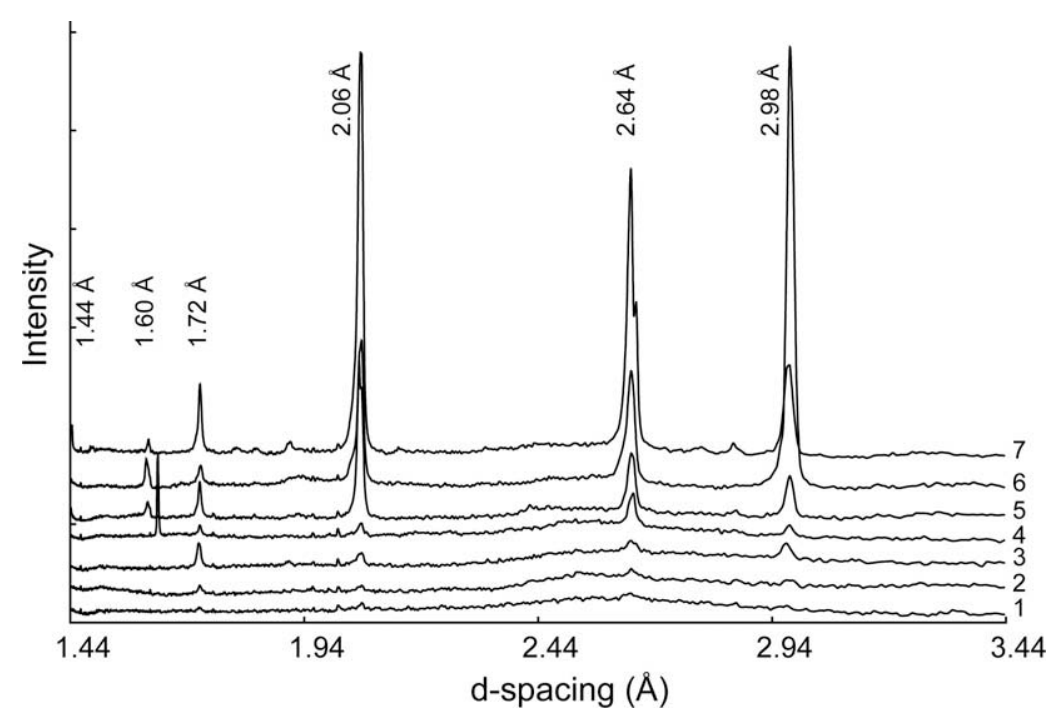

Fig. 4. X-ray diffraction patterns collected from the petrographic section at the mineralogical interface between the primary sulfides and the Fe-encrusted biofilm. The seven diffraction patterns displayed here, numbered 1-7, were collected at the numbered locations indicated on the FeSCa tricolor XRF map in Fig. 3. The labeled peaks at 1.44, 1.60, 1.72, 2.06, 2.64, and $2.98 \AA$, correspond to those of the Fe sulfide mineral pyrrhotite.

trum, and magnitude portion of the Fourier transformed data (Fig. 5B), collected from the Fe-encrusted biofilm is compared to reference spectra collected from the Fe oxyhydroxides 2-line ferrihydrite (2L FH), 6-line ferrihydrite ( $6 \mathrm{~L}$ $\mathrm{FH}$ ), and goethite. Distinct spectral differences can be observed in $k$-space $\left(5.5\right.$ and $7.5 \AA^{-1}$ ) and the second shell of the Fourier transformed data.

To better understand how Fe oxyhydroxide spectral features translate into mineral structure features, the Fe EXAFS spectrum collected from goethite was examined through shell-by-shell fitting and simulation of different arrangements of $\mathrm{Fe}-\mathrm{O}_{6}$ octahedra. The results of the multi-shell fit to the goethite data are displayed in Fig. 6 (spectrum A) and in Table 1. From the XRD-derived crystal structure, goethite is known to have three unique $\mathrm{Fe}-\mathrm{Fe}$ interatomic distances in the second-shell of nearest neighbor atoms: two at $3.01 \AA$, two at $3.29 \AA$, and four at $3.43 \AA$. These three $\mathrm{Fe}-\mathrm{Fe}$ interatomic distances represent the three types of polyhedral linkages present in the goethite structure: edge-sharing to form single chains ( $\mathrm{Fe}-$ $\mathrm{Fe} 1$ ), edge-sharing to form double chains ( $\mathrm{Fe}-\mathrm{Fe} 2)$, and double corner-sharing ( $\mathrm{Fe}-\mathrm{Fe} 3)$, as labeled in Table 1. The interatomic distances for the fit to the second-shell goethite EXAFS data were $R(\mathrm{Fe}-\mathrm{Fe} 1)=3.03 \pm 0.01 \AA, R(\mathrm{Fe}-$ $\mathrm{Fe} 2)=3.31 \pm 0.04 \AA$, and $R(\mathrm{Fe}-\mathrm{Fe} 3)=3.43 \pm 0.02 \AA(\mathrm{Ta}-$ ble 1).

With the fit to the goethite data as a starting point, hypothetical coordination numbers $(N)$ and mean-square displacement of bond length parameters $\left(\sigma^{2}\right)$ were used to simulate $\mathrm{Fe}$ oxyhydroxide mineral structures with lower coordination numbers (i.e. missing polyhedral linkages) and greater structural disorder (i.e. greater $\sigma^{2}$ values). The results of these simulations are presented in Table 1 and Fig. 6, and are compared to the goethite and Fe-encrusted biofilm spectra. For each simulation (B-E), a structural diagram of the hypothetical $\mathrm{Fe}$ oxyhydroxide is provided. In simulation $\mathrm{B}$, the number of corner-sharing $\mathrm{Fe}-\mathrm{O}_{6}$ octahedral linkages present in the structure is reduced from $N(\mathrm{Fe}-$ $\mathrm{Fe} 3)=4$, as in goethite, to $N(\mathrm{Fe}-\mathrm{Fe} 3)=2$. In addition, the coordination number for the edge-sharing octahedra, $N(\mathrm{Fe}-\mathrm{Fe} 2)$, was reduced from 2 , as in goethite, to a value of 1 , keeping all other parameters constant. The spectral changes associated with these reductions in coordination number, $N$, manifest themselves primarily as a change in line-shape in the $k$-range of $5.0-5.8 \AA^{-1}$ (Fig. 6, region I) and a decrease in the amplitude of the oscillation in region II, $k$-range $7.0-8.0 \AA^{-1}$. In simulation $\mathrm{C}$, the corner-sharing structural feature $(\mathrm{Fe}-\mathrm{Fe} 3)$ is removed entirely from the hypothetical $\mathrm{Fe}$ oxyhydroxide structure. The simulated spectrum exhibits additional, although more subtle, changes in line-shape in region I, and decreased amplitude in region II (Fig. 6). In simulation D, the edge-sharing linkages $(\mathrm{Fe}-\mathrm{Fe} 2)$ that create double chains are removed, and the mean-square displacement of bond length parameter $\left(\sigma^{2}\right)$ for the $\mathrm{Fe}-\mathrm{Fel}$ atomic pair is increased to a value of $0.010 \AA^{2}$ from $0.002 \AA^{2}$. The progressive changes created going from simulation $\mathrm{C}$ to simulation $\mathrm{D}$ are primarily in spectral regions II and III. Specifically, the loss of the double chain structure reduces the spectral feature in region II to a shoulder, and the increase in structural disorder dampens the amplitude of the region III features. For simulation $\mathrm{E}$, the coordination number for edge-sharing octahedra (of the $\mathrm{Fe}-\mathrm{Fe} 1$ type) is increased to 4 and the $\sigma^{2}$ is set to 0.015 . The spectral differences between simulations D and E are not well resolved.

\subsubsection{Comparison of iron oxyhydroxide second-shell spectroscopic features}

The second shell $\mathrm{Fe}-\mathrm{Fe}$ atom pair contributions to the Fe EXAFS data were isolated for goethite, 6L FH, 2L $\mathrm{FH}$, and the Fe-encrusted biofilm through Fourier filtering (Fig. 7). In this analysis, with a $k$-space data range of $2-$ 

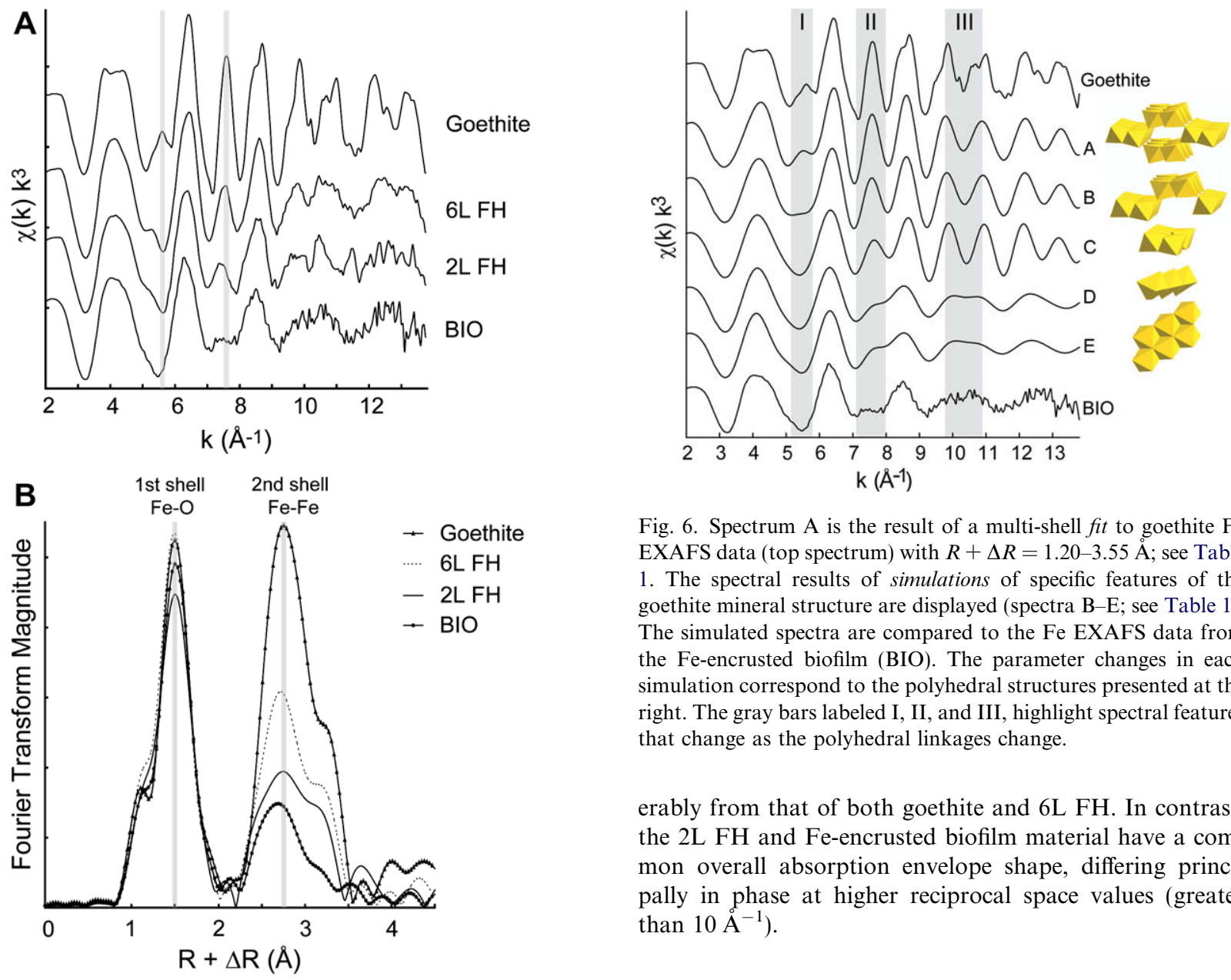

Fig. 6. Spectrum $\mathrm{A}$ is the result of a multi-shell fit to goethite $\mathrm{Fe}$ EXAFS data (top spectrum) with $R+\Delta R=1.20-3.55 \AA$; see Table 1. The spectral results of simulations of specific features of the goethite mineral structure are displayed (spectra B-E; see Table 1). The simulated spectra are compared to the Fe EXAFS data from the Fe-encrusted biofilm (BIO). The parameter changes in each simulation correspond to the polyhedral structures presented at the right. The gray bars labeled I, II, and III, highlight spectral features that change as the polyhedral linkages change.

erably from that of both goethite and $6 \mathrm{~L} \mathrm{FH.} \mathrm{In} \mathrm{contrast,}$ the $2 \mathrm{~L} \mathrm{FH}$ and Fe-encrusted biofilm material have a common overall absorption envelope shape, differing principally in phase at higher reciprocal space values (greater than $10 \AA^{-1}$ ).

\subsubsection{Shell-by-shell fits to $6 \mathrm{~L} \mathrm{FH,} 2 \mathrm{~L} \mathrm{FH}$, and biofilm EXAFS data}

The short-range structure of the $6 \mathrm{~L} \mathrm{FH}$ and $2 \mathrm{~L} \mathrm{FH}$ refencrusted biofilm (BIO) is compared to those collected from laboratory synthesized Fe oxyhydroxides, goethite, 6-line ferrihydrite $(6 \mathrm{~L} \mathrm{FH})$, and 2-line ferrihydrite (2L FH). (B) The magnitude portion of the Fourier transformed data is also compared among the Fe oxyhydroxides.

13.8 $\AA^{-1}$, the distance resolution (ability to identify different $\mathrm{Fe}-\mathrm{Fe}$ subshells $)$ is approximately $0.11 \AA\left(k_{\max } \geqslant \pi /\right.$ $\left.(2 \Delta R), \Delta R=\left|R_{1}-\mathrm{R}_{2}\right|\right)$ (Manceau and Drits, 1993). This distance resolution should be sufficient to distinguish among the three $\mathrm{Fe}-\mathrm{Fe}$ subshells in our model $\mathrm{Fe}$ oxyhydroxide goethite, e.g., $\quad R(\mathrm{Fe}-\mathrm{Fe} 3)-R(\mathrm{Fe}-\mathrm{Fe} 2)=0.14 \AA \quad$ and $R(\mathrm{Fe}-\mathrm{Fe} 2)-R(\mathrm{Fe}-\mathrm{Fe} 1)=0.28 \AA$. The Fe-encrusted biofilm second-shell EXAFS spectrum is compared to that of goethite in Fig. 7A. A distinct beat node feature (arrow, Fig. 7A) is present in the goethite FT filtered spectrum at 4.6 $\AA^{-1}$, corresponding to a $\Delta R$ value of $0.14 \AA$, indicating that at least two $\mathrm{Fe}-\mathrm{Fe}$ subshells are contributing to the EXAFS spectrum (Manceau and Drits, 1993). A beat node feature (arrow, Fig. 7B) is present in the 6L FH FT filtered spectrum at $11.25 \AA^{-1}$, corresponding to a $\Delta R$ value of $0.34 \AA$. Neither the $2 \mathrm{~L} \mathrm{FH}$ or the Fe-encrusted biofilm spectrum exhibit any beat node features in this data range. The line-shape, amplitude, and phase character of the Fe-encrusted biofilm $\mathrm{Fe}-\mathrm{Fe}$ second-shell spectrum differs considerence minerals and the Fe-encrusted biofilm material was assessed through fitting of the Fourier transformed $k^{3}$ weighted EXAFS data. The $6 \mathrm{~L} \mathrm{FH}$ and $2 \mathrm{~L} \mathrm{FH}$ spectra were FT filtered in the $R+\Delta R$ range of $1-3.55$ and $1-$ $3.47 \AA$, respectively, and fit with two $\mathrm{Fe}-\mathrm{O}$ atom pairs in the first-shell and two $\mathrm{Fe}-\mathrm{Fe}$ atom pairs in the second-shell (Fig. 8A and B and Table 2). In the 6L FH second-shell, an $\mathrm{Fe}-\mathrm{Fe} 1$ subshell was fit at a distance of $R(\mathrm{Fe}-\mathrm{Fe} 1)=3.03 \pm 0.01 \AA$; this value is consistent with edge-sharing octahedral linkages. A second, Fe-Fe3, subshell was fit at a distance of $R(\mathrm{Fe}-\mathrm{Fe} 3)=3.43 \pm 0.02 \AA$ : consistent with double corner-sharing octahedral linkages. These interatomic distances are in agreement with those reported by Manceau and Drits (1993), where 6L FH fits consisted of $3.0 \mathrm{Fe}-\mathrm{Fe} 1$ at $3.01 \AA$ and $6.5 \mathrm{Fe}-\mathrm{Fe} 3$ at $3.44 \AA$ (Table 3). In the second-shell data for $2 \mathrm{~L} \mathrm{FH}$, an $\mathrm{Fe}-\mathrm{Fe} 1$ subshell was fit at a distance of $R(\mathrm{Fe}-$ $\mathrm{Fe} 1)=3.05 \pm 0.02 \AA$, and a second $\mathrm{Fe}-\mathrm{Fe} 3$ subshell was fit at a distance of $R(\mathrm{Fe}-\mathrm{Fe} 3)=3.45 \pm 0.02 \AA$ (Table 2). As with $6 \mathrm{~L} \mathrm{FH}$, these values are in agreement with those reported in the literature (Table 3). In the second-shell data for the $\mathrm{Fe}$-encrusted biofilm, an $\mathrm{Fe}-\mathrm{Fe} 1$ subshell was fit at a distance of $R(\mathrm{Fe}-\mathrm{Fe} 1)=3.06 \pm 0.01 \AA$ with coordination number $N(\mathrm{Fe}-\mathrm{Fe} 1)=3.3 \pm 1.2$, and $\sigma^{2}(\mathrm{Fe}-$ 
Table 1

Summary of Fe EXAFS parameters for goethite fit and simulations presented in Fig. 6. The second shell polyhedral relationships that create the $\mathrm{Fe}-\mathrm{Fe} 1, \mathrm{Fe}-\mathrm{Fe} 2$, and $\mathrm{Fe}-\mathrm{Fe} 3$ atom pairs are illustrated with polyhedral representations of goethite.

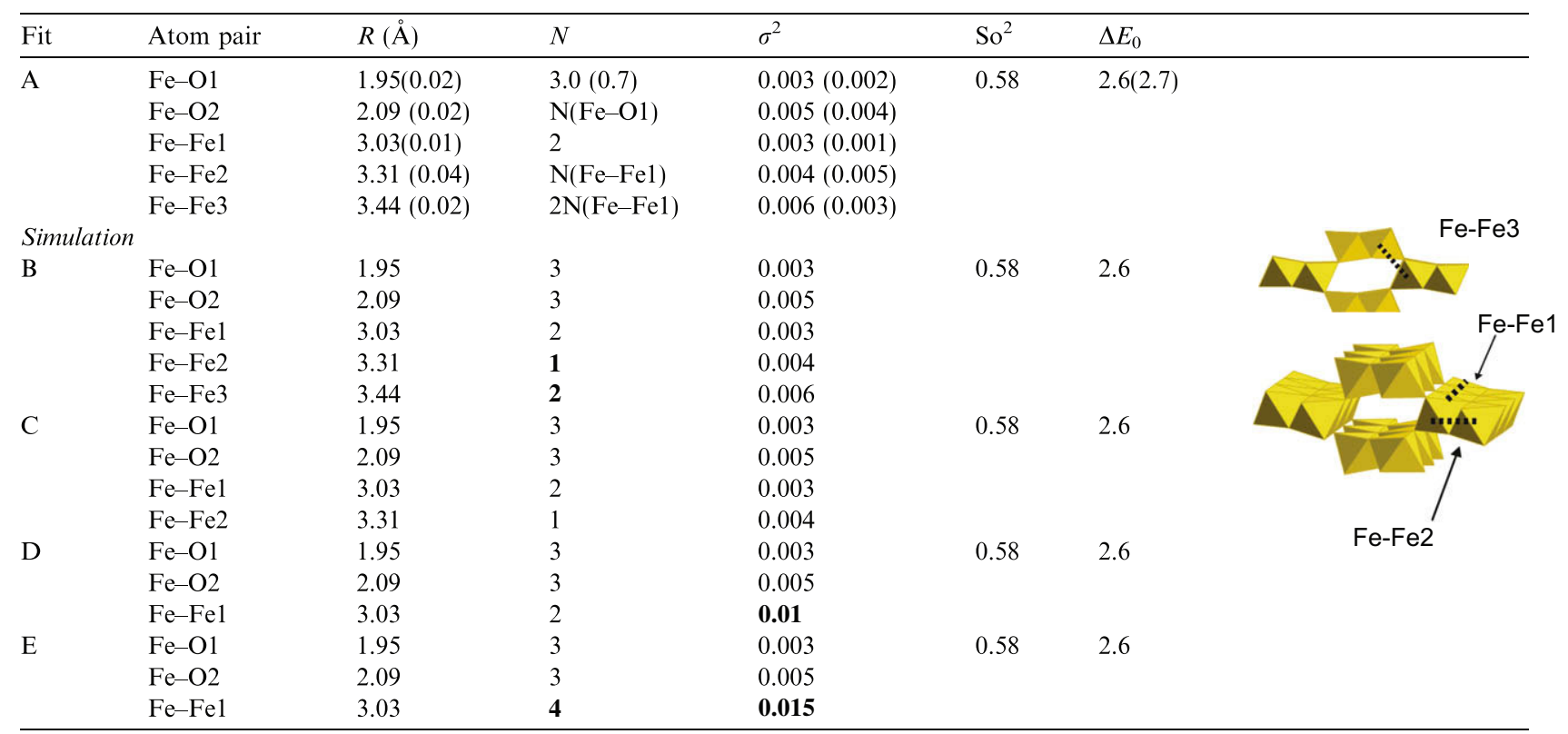

For fit A and simulations B-E, $R$ is interatomic distance, $N$ is coordination number, and $\sigma^{2}\left(\AA^{2}\right)$ is the mean-square displacement of bond length, $S_{0}{ }^{2}$ is the amplitude reduction factor, and $\Delta E_{0}$ is the threshold energy. The parameter error estimates for fit $\mathrm{A}$ are reported in parentheses. The $k$-range for fit A was 2-13.8 $\AA^{-1}, R$-range of $1.20-3.55 \AA$, the reduced chi square $\left(\chi_{v}{ }^{2}\right)=232$, and $R$-factor $=0.02$. Parameter values lacking error estimates were set during simulations. B-E are not fits to data but are simulations of spectra having set $R, N$, and $\sigma^{2}$ values corresponding to specific polyhedral arrangements. For the parameters reported for simulations B-E, the parameters in bold face type indicate those changed from the previous simulation.

Fe1 $)=0.014 \pm 0.003 \AA^{2}$. Although a slight shoulder feature on the high- $R$ side of the FT second-shell is visible, a second $\mathrm{Fe}-\mathrm{Fe} 2$ or $\mathrm{Fe}-\mathrm{Fe} 3$ subshell was not supported by the data. Therefore, edge-sharing octahedral linkages are present in the Fe-encrusted biofilm and, at the level of detection for EXAFS, double-corner sharing octahedral linkages are absent.

\section{DISCUSSION}

\subsection{Diffraction of electrons and X-rays at nano- and micrometer spatial scales}

The Juan de Fuca Ridge chimney sulfide mineral chip was the most heavily colonized of the polished minerals incubated at the seafloor (Edwards et al., 2003a). The accumulation of Fe-encrusted biofilms (composed of cells, extracellular structures, and mineral particles) occurred above pits and inside the pores of the sulfide mineral assemblage (Fig. 3A). These accumulations were densely populated with particles of twisted stalk morphologies consistent with microbiological production (Fig. EA-1C).

In our HRTEM investigation of FIB foils extracted from $\mathrm{Fe}$-encrusted biofilms, nanoparticles with lattice fringes were infrequently observed. Due to the random orientation of the individual nanoparticles, only those which are just by chance oriented with a low-index zone axis parallel to the electron beam will show lattice fringes. Where lattice fringes were observed, electron diffraction patterns with weak, diffuse rings and/or spots were collected. The observed 2.60 and $1.56 \AA d$-spacings are in agreement with those reported for synthetic and microbiologically produced 2-line ferrihydrite (Jambor and Dutrizac, 1998; Banfield et al., 2000; Janney et al., 2000), as well as those reported by Edwards et al. (2003a) for subsamples of the same Fe-encrusted biofilm. The $2.14 \AA$ band may be produced by ferrihydrite (Jambor and Dutrizac, 1998) or a sulfide mineral. However, EDX spectra from sample locations where TEM was conducted agree with XRF results and indicate that the $\mathrm{S}$ concentration is very low (Figs. EA-4 and EA-5). Iron EXAFS data would be very sensitive to the presence of a Fe sulfide mineral. We detect only $\mathrm{Fe}(\mathrm{III})$, and this suggests that if a nanoparticulate Fe sulfide mineral is present, then it must be below $\sim 5 \%$ of the $\mathrm{Fe}$ in the biofilm.

Sample damage is a concern for FIB prepared foils (Benzerara et al., 2005; Obst et al., 2005; Lee et al., 2007). For minerals such as calcite, the potential depth of side-wall sample damage was modeled by Obst et al. to be approximately $20-30 \mathrm{~nm}$. The primary concern for our biogenic Fe oxyhydroxide mineral is that FIB artifacts may cause the mineral to appear more amorphous than it is in reality. Our complementary measurements provide evidence that the HRTEM data from FIB-prepared foils are valid. The FT and HRTEM data we present for the FIB sample are in agreement with HRTEM and SAED measurements obtained for subsamples of non-FIB treated biogenic Fe oxyhydroxides (Edwards et al., 2003a). The $\mu \mathrm{XRD}$ and $\mathrm{Fe}$ 
EXAFS spectroscopy measurements collected from nonFIB samples indicate that the biogenic Fe oxyhydroxides are essentially XRD amorphous and have less 3-dimensional character than 2-line ferrihydrite.

With a probe spot size of $15 \times 8.5 \mu \mathrm{m}$, synchrotron-radiation XRD patterns collected from the Fe-encrusted biofilm exhibit only one weak, broad (2.2-3.0 ̊) diffraction feature centered at approximately $2.6 \AA$ (Fig. 4, patterns 1-4). When compared, data from the nanometer scale (HRTEM) and micrometer scale ( $\mu$ XRD) indicate that certain particles in the biofilm have a crystal structure consistent with 2-line ferrihydrite, but that the majority of the Fe is present in particles that lack long-range order sufficient to produce 2-line ferrihydrite diffraction patterns. A mixture of abiotic and biotic $\mathrm{Fe}$ oxidation products are often produced by microbial mats and pure cultures (Emerson and Moyer, 2002; Rentz et al., 2007). It is possible that the observed aggregates of ferrihydrite nanoparticles are formed by abiotic $\mathrm{Fe}(\mathrm{II})$ oxidation processes within the biofilm. In agreement with previous studies of mineral-forming biofilms in general (Moreau et al., 2007) and Fe-oxidizing microorganisms in particular (Chan et al., 2004), our findings illustrate the very fine spatial scale at which chemical and mineralogical heterogeneity exists in microbial systems and how averaging over small areas of biofilm (from $1 \mathrm{~nm}^{2}$ to $10 \mu \mathrm{m}^{2}$ ) can change the observed properties of the system.

The $\mu \mathrm{XRD}$ measurements reveal that the Fe-encrusted biofilms are rooted in and intermixed with pyrrhotite-rich regions of the primary chimney sulfide (Figs. 3 and 4, patterns 3-7). The pyrite crystals exposed at the surface of the incubated chip did not host Fe-encrusted biofilms. If the Fe-encrusted biofilm used pyrrhotite as a source of reduced $\mathrm{Fe}$, then the preference for pyrrhotite may be due to the differences in the reactivity of the two minerals with oxygen; $1.4 \times 10^{-8} \mathrm{~mol} \mathrm{~m}^{-2} \mathrm{~s}^{-1}$ for pyrrhotite $(\mathrm{pH} 2-6)$ and $5.3 \times 10^{-10} \mathrm{~mol} \mathrm{~m}^{-2} \mathrm{~s}^{-1}$ for pyrite (average for $\mathrm{pH}$ values 1-8) (Nordstrom and Alpers, 1999). Differences in reactivity between pyrrhotite and pyrite in our chimney sulfide chip may also result from the porosity of pyrrhotite crystals with boxwork textures, e.g., 10-15\% (Koski et al., 1988). Large differences in microbial colonization of specific sulfide minerals within mixed sulfide mineral assemblages have been observed in the laboratory (Lawrence et al., 1997). Lawrence et al. found that Thiobacillus ferrooxidans preferentially colonized pyrrhotite over pyrite in a two-sulfide component system $(>50 \%$ surface coverage versus $0-10 \%$, respectively). In the pyrrhotite-pyrite system, microelectrode measurements indicated that microorganisms accumulated at the anode of a galvanic cell (pyrrhotite) and promoted extensive weathering in that location. These results are consistent with the spatial distribution of microbial biofilm development that we observe in our study of microbial sulfide weathering under seafloor conditions (Edwards et al., 2003a).

\subsection{Biogenic iron oxyhydroxide structure is composed of edge-sharing octahedral units}

Similarities among the reference spectra $(2 \mathrm{~L} \mathrm{FH}, 6 \mathrm{~L} \mathrm{FH}$, and goethite) and the Fe-encrusted biofilm spectrum in- clude overall line-shape, phase, and amplitude characteristics. As $2 \mathrm{~L} \mathrm{FH,} \mathrm{6L} \mathrm{FH,} \mathrm{and} \mathrm{goethite} \mathrm{contain} \mathrm{Fe}(\mathrm{III})-\mathrm{O}_{6}$ octahedra as the primary structural unit, we infer that the Fe-encrusted biofilm material also has this basic structural unit. Therefore, the Fe-encrusted biofilm material can be viewed as a short-range ordered Fe oxyhydroxide mineral, produced by biological activities; in the following discussion this mineral will be referred to as "biogenic iron oxyhydroxide" or BIO. The Fe EXAFS spectra considered in Fig. 5 also possess significant spectral differences, reflecting the way in which the $\mathrm{Fe}(\mathrm{III})-\mathrm{O}_{6}$ octahedra are linked together, e.g., face-, edge-, and corner-sharing polyhedra, differs among the $\mathrm{Fe}$ oxyhydroxides considered here. The suite of $\mathrm{Fe}(\mathrm{III})-\mathrm{O}_{6}$ octahedral linkages present in an $\mathrm{Fe}$ oxyhydroxide form the basis of mineralogical structure, and results in different $\mathrm{Fe}-\mathrm{Fe}$ interatomic distances and coordination numbers (Combes et al., 1989; Manceau and Drits, 1993). The variety of polyhedral linkages present in the $\mathrm{Fe}$ oxyhydroxides, as indicated by the $\mathrm{Fe}-\mathrm{Fe}$ interatomic distances measured, can be readily observed in the shape of the second shell of the Fourier transform of the Fe EXAFS spectra (Fig. 5B).

Simulations of specific arrangements of $\mathrm{Fe}-\mathrm{O}_{6}$ octahedra-starting with a goethite structure consisting of edgesharing $\mathrm{Fe}-\mathrm{O}_{6}$ octahedra to form single chains, edge-sharing $\mathrm{Fe}-\mathrm{O}_{6}$ octahedra to form double chains, and double cornersharing $\mathrm{Fe}-\mathrm{O}_{6}$ octahedra to form linkages between double chains - reveal several spectral indicator regions that correspond to polyhedral linkages (Fig. 6). By comparing EXAFS simulations to our $\mathrm{BIO}$ spectrum, we surmise that the $\mathrm{BIO}$ is constructed primarily of edge-sharing $\mathrm{Fe}-\mathrm{O}_{6}$ octahedra and is two-dimensional in structure. The spectral features corresponding to corner-sharing $\mathrm{Fe}-\mathrm{O}_{6}$ octahedral linkages, regions I and II, are diminished greatly or absent in the BIO relative to goethite, $6 \mathrm{~L} \mathrm{FH}$, and $2 \mathrm{~L} \mathrm{FH}$.

A two-dimensional structural view (i.e. chain or planar arrangement of edge-sharing $\mathrm{Fe}-\mathrm{O}_{6}$ polyhedra) of the BIO is further supported by shell-by-shell fitting of EXAFS data in the range of $k=2-13.8 \AA^{-1}$ (Fig. 8 and Table 2). The Fe oxyhydroxide minerals considered here form a continuum in structure, from goethite to $2 \mathrm{~L} \mathrm{FH}$, where the short-range structural order decreases. The BIO represents a continuation of this trend, representing a Fe oxyhydroxide mineral with less structural order and three-dimensional character than our 2L FH reference (Fig. 5). The shell-byshell fitting of $6 \mathrm{~L} \mathrm{FH,} \mathrm{2L} \mathrm{FH,} \mathrm{and} \mathrm{data} \mathrm{reveal} \mathrm{two} \mathrm{struc-}$ tural trends (from $6 \mathrm{~L} \mathrm{FH}$ to $2 \mathrm{~L} \mathrm{FH}$, and finally to the BIO, Table 2): (1) increasing disorder in the edge-sharing linkages, as indicated by our observation of increasing $\sigma^{2}(\mathrm{Fe}-\mathrm{Fe} 1)$ values, and (2) decreasing number of cornersharing octahedral linkages, as indicated by our observation of $N(\mathrm{Fe}-\mathrm{Fe} 3)$ decreasing from $2.4 \pm 1.5$ for $6 \mathrm{~L} \mathrm{FH}$ to zero in the case of Table 2. In the second-shell of the BIO data, an $\mathrm{Fe}-\mathrm{Fel}$ atom pair was fit at a distance of $3.07 \pm 0.01 \AA$ (Fig. 8C and Table 2). The best fit coordination number $(N)$ for this $\mathrm{Fe}-\mathrm{Fe} 1$ subshell was $3.3 \pm 1.2$ with a range from 2.1 to 4.5 . Within that range of $N$ values, different edge-sharing configurations of $\mathrm{Fe}-\mathrm{O}_{6}$ octahedra are possible. For example, long single chains of edge-sharing octahedra would have a coordination number approaching 

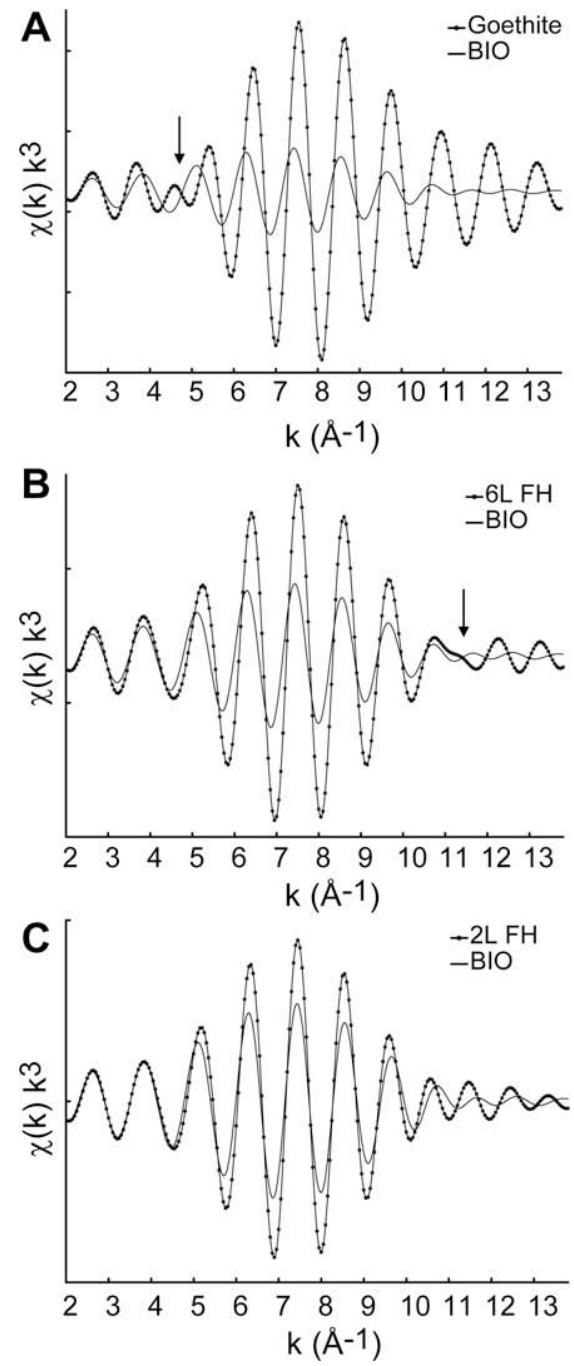

Fig. 7. Fourier-filtered second shell data for the Fe-encrusted biofilm (BIO; $R+\Delta R$ range 2.24-3.37 $\mathrm{A}$ ), 2-line ferrihydrite ( $2 \mathrm{~L}$ $\mathrm{FH} ; \quad R+\Delta R$ range $2.20-3.47 \AA$ ), 6-line ferrihydrite $(6 \mathrm{~L} \mathrm{FH}$; $R+\Delta R$ range $2.05-3.55 \AA)$, and goethite $(R+\Delta R$ range 2.09 $3.55 \AA$ ). The arrows in panels (A) and (B) indicate beat node patterns from split shells in the $6 \mathrm{~L} \mathrm{FH}$ and goethite filtered spectra, respectively. The $k$-range for the raw EXAFS data was $2-13.8 \AA^{-1}$. In all panels, the $y$-axis interval is $2\left(\AA^{-3}\right)$.

2. Tetramers with a goethite-like double chain structure, consisting entirely of edge-sharing linkages, would have an $N$ equal to 2.5. If a double chain configuration is sufficiently long, then the total $N$ for edge-sharing approaches a value of 4. A planar, sheet-like arrangement of edge-sharing $\mathrm{Fe}-\mathrm{O}_{6}$ octahedra would approach an $N$ of 6 . Therefore, the exact configuration of edge-sharing $\mathrm{Fe}-\mathrm{O}_{6}$ octahedra in the BIO particles is not resolved here with Fe EXAFS measurements; particles containing single- and double chains, as well as small planar sheets of edge-sharing $\mathrm{Fe}-\mathrm{O}_{6}$ octahedra are supported by the $N$ values obtained from shell-byshell fitting.

The $\mathrm{Fe}-\mathrm{Fe} 1$ interatomic distance obtained for the $\mathrm{BIO}$ is consistent with edge-sharing polyhedral linkages associated with $\mathrm{Fe}$ polymerization products (Manceau and Drits, 1993), ferric hydrous oxide gels (Combes et al., 1989), 2L
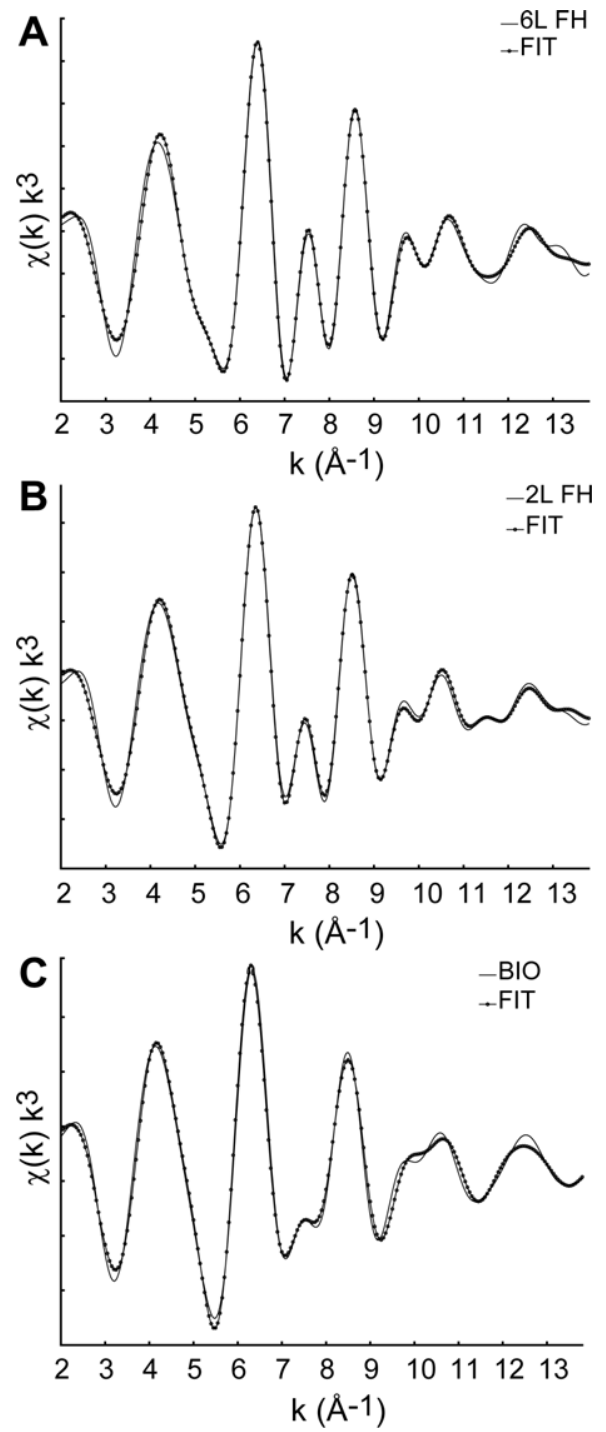

Fig. 8. Multi-shell fit to Fe EXAFS data for 6-line ferrihydrite (6L $\mathrm{FH} ; \quad 1-3.55 R+\Delta R \quad \AA), \quad$-line ferrihydrite $(2 \mathrm{~L} \quad \mathrm{FH}$; $1-3.47 R+\Delta R \AA$ ), and the Fe-encrusted biofilm (BIO; $1-3.37 R+\Delta R \AA$ ). The fit parameters are presented in Table 2 . In all fits, the $k$-range was $2-13.8 \AA^{-1}$.

FH ( Manceau and Drits, 1993; Waychunas et al., 1996, 2002; Chatellier et al., 2004; O'Day et al., 2004), 6L FH (Manceau and Drits, 1993), and goethite (Waychunas et al., 1996; O'Day et al., 2004) having an Fe-Fel interatomic distance in the range of 3.00-3.07 $\AA$ (Table 3). A striking difference between the BIO and all of the Fe polymers, oxides, and oxyhydroxides listed in Table 3 is its lack of $\mathrm{Fe}-\mathrm{Fe} 3$ path in the $R$-range of 3.39-3.45 $\AA$. In effect this structure represents a step along the polymerization pathway of oxyhydroxide formation. Why is the polymerization and crystallization of BIO suspended?

\subsection{Sorption of ligands inhibits development of iron oxyhydroxide crystallinity}

Conditions leading to limited crystallinity in Fe oxyhydroxides can include rapid rate of hydrolysis reactions 
Table 2

Summary of multi-shell fit parameters for 6-line ferrihydrite (6L FH), 2-line ferrihydrite (2L FH), and the Fe-encrusted biofilm (BIO).

\begin{tabular}{|c|c|c|c|c|c|c|c|c|c|c|}
\hline & $N$ & & $R(\AA)$ & & $\sigma^{2}\left(\AA^{2}\right)$ & & $R$-range & & $R$-factor & \\
\hline \multicolumn{11}{|c|}{ 6L FH atom pair } \\
\hline $\mathrm{Fe}-\mathrm{O} 1$ & 3.3 & 0.4 & 1.93 & 0.01 & 0.003 & 0.001 & 2.0 & 1.5 & $1-3.55$ & 0.013 \\
\hline $\mathrm{Fe}-\mathrm{O} 2$ & $N(\mathrm{Fe}-\mathrm{O} 1)$ & - & 2.07 & 0.02 & 0.006 & 0.003 & & & & \\
\hline $\mathrm{Fe}-\mathrm{Fe} 1$ & 3.0 & 1.3 & 3.03 & 0.02 & 0.009 & 0.003 & & & & \\
\hline $\mathrm{Fe}-\mathrm{Fe} 3$ & 2.4 & 1.5 & 3.43 & 0.02 & 0.008 & 0.005 & & & & \\
\hline \multicolumn{11}{|c|}{$2 L F H$ atom pair } \\
\hline $\mathrm{Fe}-\mathrm{O} 1$ & 2.7 & 0.3 & 1.92 & 0.01 & 0.003 & 0.002 & 1.3 & 1.4 & $1-3.47$ & 0.010 \\
\hline $\mathrm{Fe}-\mathrm{O} 2$ & $N(\mathrm{Fe}-\mathrm{O} 1)$ & & 2.04 & 0.01 & 0.005 & 0.002 & & & & \\
\hline $\mathrm{Fe}-\mathrm{Fe} 1$ & 3.5 & 1.7 & 3.05 & 0.02 & 0.013 & 0.004 & & & & \\
\hline $\mathrm{Fe}-\mathrm{Fe} 3$ & 1.4 & 1.0 & 3.45 & 0.02 & 0.006 & 0.005 & & & & \\
\hline \multicolumn{11}{|c|}{ BIO atom pair } \\
\hline $\mathrm{Fe}-\mathrm{O} 1$ & 2.8 & 0.3 & 1.94 & 0.01 & 0.003 & 0.001 & 2.7 & 1.2 & $1-3.37$ & 0.015 \\
\hline $\mathrm{Fe}-\mathrm{O} 2$ & $N(\mathrm{Fe}-\mathrm{O} 1)$ & & 2.07 & 0.01 & 0.005 & 0.002 & & & & \\
\hline $\mathrm{Fe}-\mathrm{Fe} 1$ & 3.3 & 1.2 & 3.06 & 0.01 & 0.014 & 0.003 & & & & \\
\hline
\end{tabular}

$R$ is the interatomic distance, $N$ is the coordination number, $\sigma^{2}$ is the mean-square displacement of bond length, and $\Delta E_{0}$ is the threshold energy. The parameter error estimates are reported in the second column. The $k$-range was $2-13.8 \AA^{-1}$. The Fourier-filtered data $R$-range is reported above.

and the presence of organic or inorganic ligands during Fe(III) polymerization (Cornell and Schwertmann, 1979; Vilge-Ritter et al., 1999; Schwertmann et al., 2004). The effects of inorganic ligands such as $\mathrm{SiO}_{4}, \mathrm{SO}_{4}, \mathrm{PO}_{4}$, and $\mathrm{AsO}_{4}$ on $\mathrm{Fe}(\mathrm{III})$ hydrolysis reactions and the resulting $\mathrm{Fe}$ oxyhydroxide mineral structure have been examined in detail with Fe EXAFS measurements (Rose et al., 1996, 1997; Waychunas et al., 1996; Masion et al., 2001; Doelsch et al., 2003; Chatellier et al., 2004). For example, the presence and relative concentration of $\mathrm{SiO}_{4}$ in solution during $\mathrm{Fe}(\mathrm{III})$ polymerization appears to exert strong control over the extent of $\mathrm{Fe}$ oxyhydroxide crystallization. In general, $\mathrm{Si} / \mathrm{Fe}<1$ leads to three-dimensional crystal structures that exhibit edge- and corner-sharing $\mathrm{Fe}-\mathrm{O}_{6}$ octahedra, while conditions of $\mathrm{Si} / \mathrm{Fe}>1$ favor edge-sharing $\mathrm{Fe}-\mathrm{O}_{6}$ octahedra with two-dimensional structures (Doelsch et al., 2003). While silicate ions are effective at limiting the formation of cornersharing linkages in $\mathrm{Fe}$ oxyhydroxide precipitates, phosphate and arsenate ions at specific concentrations can completely prevent the formation of these structural features. For example, with a $\mathrm{P} / \mathrm{Fe}=0.2$, no corner-sharing structural linkages were detected in a $\mathrm{Fe}(\mathrm{III})$ hydrolysis precipitate (Rose et al., 1996). Similarly, the co-precipitation of $\mathrm{AsO}_{4}$ and $\mathrm{Fe}(\mathrm{III})$ at $\mathrm{As} / \mathrm{Fe} \geqslant 0.6$ results in $\mathrm{Fe}$ oxyhydroxide particles consisting of about $4-10 \mathrm{Fe}-(\mathrm{O}, \mathrm{OH})_{6}$ octahedral units linked by edge-sharing configurations as double chains or small sheets (Waychunas et al., 1996).

\subsection{Proposed mechanism for microbiological iron sulfide oxidation at the seafloor}

We have observed that bacterial biofilms-fluorescent in situ hybridization and epi-fluorescent microscopy (Edwards et al., 2003a) - grow preferentially on the sulfide mineral pyrrhotite ( $\mu$ XRD; Figs. 3 and 4 ) at ambient deep-sea conditions at the Juan de Fuca Ridge. These biofilms are dominated by particles with twisted stalk morphologies (SEM; Fig. EA-1C) similar to those produced by Fe-oxidizing microorganisms such as Mariprofundus (Emerson et al.,
2007) and Gallionella (Hallbeck et al., 1993). The twisted stalks we observe are encrusted in Fe oxyhydroxide minerals with stunted crystallinity — consistent with $\mathrm{Fe}(\mathrm{III})$ polymerization in the presence of a high concentration of $\mathrm{Fe}$-complexing ligands (Fe EXAFS; Fig. 8 and Table2). In contrast to the stalks, no $\mathrm{Fe}$ oxyhydroxide surface precipitation was observed on pyrrhotite crystals closely associated with the biofilm (SEM of petrographic section; data not shown). From these observations we infer that bacteria present in the pyrrhotite-associated biofilm are $\mathrm{Fe}$-oxidizing organisms. If these organisms were to grow via Fe oxidation, autotrophically with oxygen as a terminal electron acceptor, and in a manner consistent with our observations, physical/chemical/biological mechanisms must exist for: (1) pyrrhotite dissolution and release of $\mathrm{Fe}(\mathrm{II})$, (2) protection of $\mathrm{Fe}(\mathrm{II})$ from oxidation to $\mathrm{Fe}(\mathrm{III})$ by dissolved oxygen, (3) transport of $\mathrm{Fe}(\mathrm{II})$ to the $\mathrm{Fe}$ oxidase, (4) $\mathrm{Fe}$ (II) oxidation to $\mathrm{Fe}(\mathrm{III})$ with an electron passed to the cell, and (5) controlled Fe(III) hydrolysis and polymerization on twisted stalks.

Abiotically, the oxidative dissolution of pyrrhotites in the presence of dissolved oxygen or $\mathrm{Fe}(\mathrm{III})$ at low $\mathrm{pH}$ appears to proceed via oxidation of $\mathrm{S}$ at the mineral surface, and results in the release of $\mathrm{Fe}(\mathrm{II})$ and the formation of a S-enriched surface layer (Janzen et al., 2000; Mikhlin and Tomashevich, 2005). At neutral $\mathrm{pH}$, and in the presence of oxygen, the $\mathrm{Fe}(\mathrm{II})$ released from solution accumulates at the pyrrhotite surface as $\mathrm{Fe}(\mathrm{III})$ oxyhydroxide precipitates (Mikhlin and Tomashevich, 2005).

For an Fe-oxidizing microbial biofilm growing on pyrrhotite at the seafloor (at $\mathrm{pH} 7.8$ and in the presence of dissolved oxygen), inhibition of abiotic Fe(II) oxidation, and transport of $\mathrm{Fe}(\mathrm{II})$ to the $\mathrm{Fe}$ oxidase is an important challenge. In this step, we hypothesize that Fe-oxidizing microorganisms limit competition between biotic and abiotic oxidation of dissolved Fe(II) by: (1) lowering the dissolved oxygen concentrations within the biofilm, (2) lowering the $\mathrm{pH}$ within the biofilm, and (3) producing ligands that complex $\mathrm{Fe}(\mathrm{II})$, denoted $\mathrm{Fe}(\mathrm{II})-\mathrm{L}$ in Fig. 9. Evidence exists for the proposed low-oxygen strategy; for example, low-oxygen 
Table 3

Summary of Fe EXAFS derived $\mathrm{Fe}-\mathrm{Fe}$ interatomic distances $(R)$ and coordination numbers $(N)$ from the literature for $\mathrm{Fe}$ (oxyhydr)oxide minerals, and $\mathrm{Fe}$ hydrolysis and polymerization products formed in the presence of oxyanions.

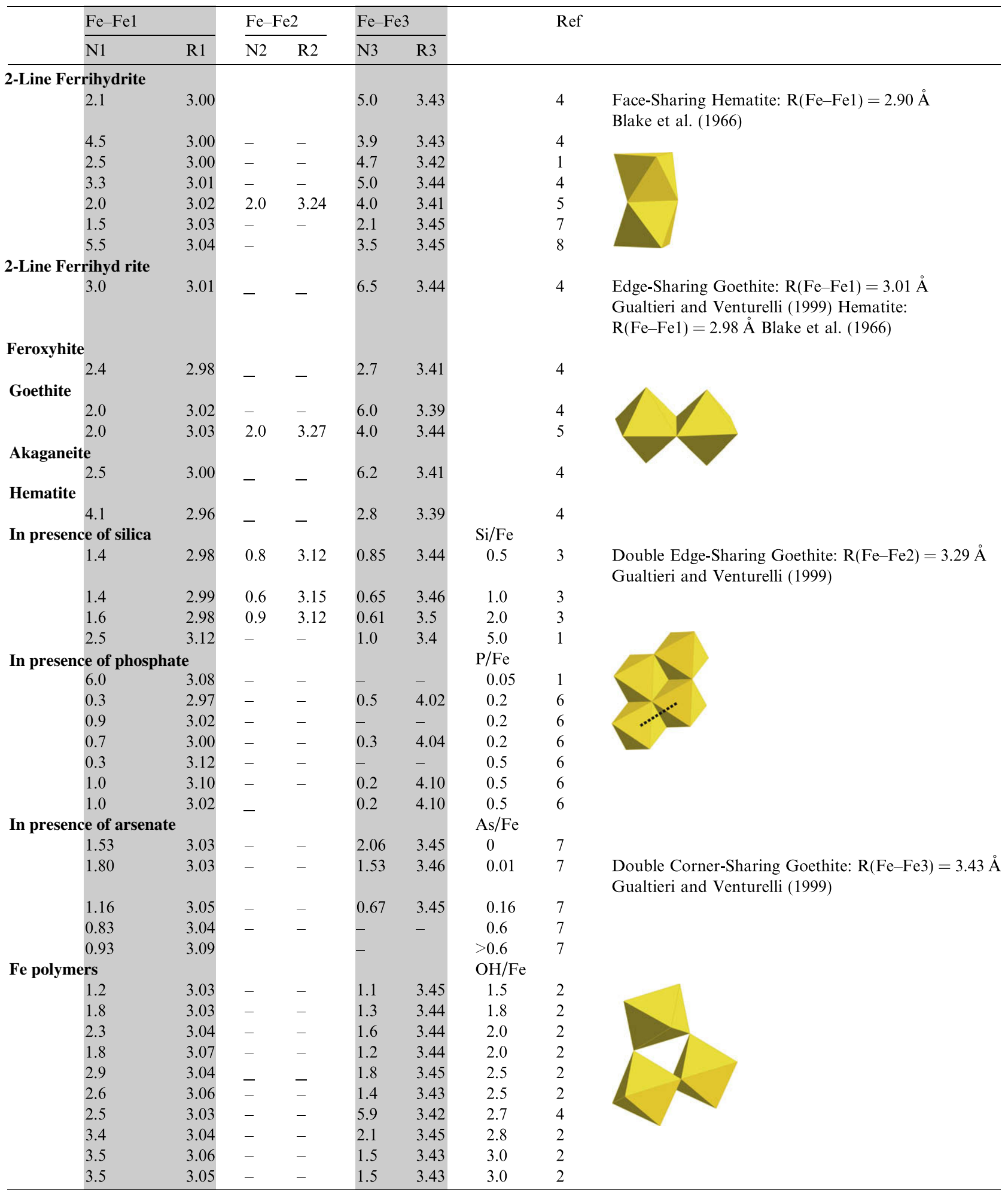

References: (1) Chatellier et al. (2004), (2) Combes et al. (1989), (3) Masion et al. (2001), (4) Manceau and Drits (1993), (5) O’Day et al. (2004), (6) Rose et al. (1996), (7) Waychunas et al. (1996), and (8) Waychunas et al. (2002).

concentrations were observed in gradient tube cultures of Juan de Fuca Fe-oxidizing isolates (Edwards et al., 2003b), and maximum oxygen concentrations reported for a neutrophilic $\mathrm{Fe}$ oxidizer were in the range of $15-50 \mu \mathrm{M}$ 


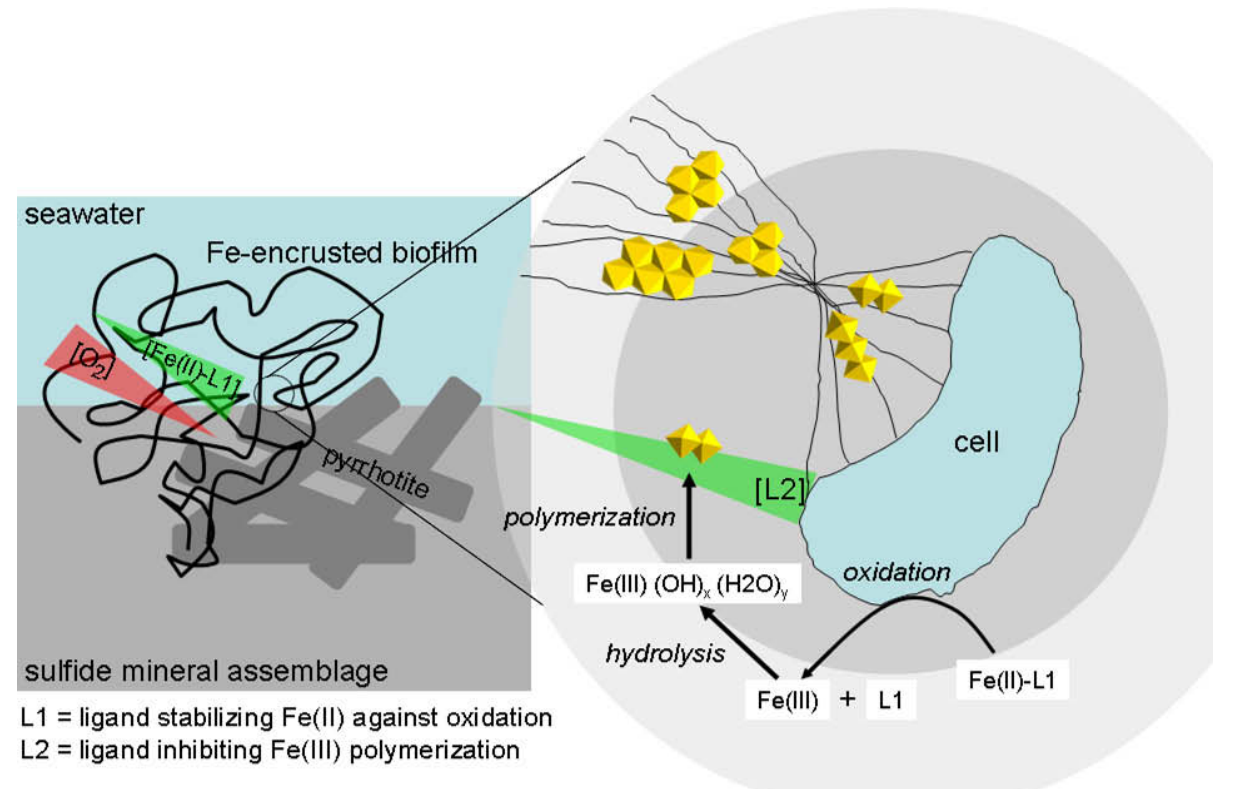

Fig. 9. Schematic representation of possible physical relationships, chemical conditions, and chemical reactions within a hypothetical Feencrusted biofilm growing on the sulfide mineral pyrrhotite at the seafloor. Triangles labeled with concentrations for $\mathrm{O}_{2}, \mathrm{Fe}(\mathrm{II})-\mathrm{L} 1$, and $\mathrm{L} 2$ represent concentration gradients where the highest concentration is at the short base of the triangle, and the lowest concentration is at the opposite tip of the triangle.

(Druschel et al., 2008). Iron-oxidizing microbes at Juan de Fuca Ridge may also be assisted by the low oxygen concentration in ambient seawater $\left(64-84 \mu \mathrm{mol} \mathrm{O} \mathrm{kg}^{-1}\right.$ seawater $)$ and resulting longer half-life of $[\mathrm{Fe}(\mathrm{II})]_{a q}\left(\tau_{1 /}\right.$ $2, \mathrm{Fe}(\mathrm{II})=6.38 \mathrm{~h})$ relative to other deep-sea locations (e.g. Rainbow Vent field 266-269 $\mu \mathrm{mol} \mathrm{O}_{2} \mathrm{~kg}^{-1}$ seawater and $\tau_{1 / 2, \mathrm{Fe}(\mathrm{II})}=0.29 \mathrm{~h}$ ) (Field and Sherrell, 2000). In addition, $\mathrm{Fe}(\mathrm{II})$-complexing ligands have been proposed as an integral component of salt-marsh Fe-cycling (Luther et al., 1992) and microbial oxidation of solid Fe(II)-bearing substrates (Edwards et al., 2004).

Next, the Fe(II)-L complex must be converted to $\mathrm{Fe}(\mathrm{III})-\mathrm{L}$ with a transfer of one electron, presumably via an oxidase. In Fig. 9, we place the oxidase at the cell outer membrane but this placement is arbitrary. Finally, the oxidized $\mathrm{Fe}$ is concentrated at the twisted stalks where crystal growth is limited. One possible mechanism for preventing extensive $\mathrm{Fe}(\mathrm{III})$ precipitates at the cell surface would be for the cell to exude soluble ligands that inhibit $\mathrm{Fe}(\mathrm{III})$ hydrolysis and polymerization, thus allowing small dissolved $\mathrm{Fe}(\mathrm{III})-\mathrm{O}_{6}$ oligomers to diffuse away from the cell and accumulate on other nearby surfaces (Roden et al., 2004) — such as the twisted stalks.

\section{CONCLUSIONS}

During a 2-month incubation at the seafloor, natural Juan de Fuca chimney sulfide assemblages were colonized by microorganisms that formed biofilms preferentially at pyrrhotite-rich regions. These bacterial biofilms were composed primarily of particles with a twisted stalk morphology resembling those produced by Fe-oxidizing microorganisms inhabiting present marine and past geo- logic settings (Emerson and Moyer, 2002; Glynn et al., 2006; Hofmann et al., 2008). Since the observed biogenic iron oxyhydroxides (BIOs) are forming within a bacterial biofilm and accumulating on twisted stalk structures (Edwards et al., 2003a), we hypothesize that dissolved organic molecules within the biofilm, and organic functional groups associated with the twisted stalks, are limiting Fe oxyhydroxide crystal growth within the pyrrhotite-associated biofilm. The spectroscopic evidence for pervasive edge-sharing $\mathrm{Fe}-\mathrm{O}_{6}$ octahedral linkages, and the absence of corner-sharing $\mathrm{Fe}-\mathrm{O}_{6}$ linkages, in the $\mathrm{BIO}$ structure is quite strong. The stunted crystallization of the BIO is consistent with the presence of Fe-complexing ligands during $\mathrm{Fe}(\mathrm{III})$ hydrolysis and polymerization. In addition to organic ligands (Vilge-Ritter et al., 1999), the Si detected within the biofilm may also contribute to the lack of three-dimensional structural features within the BIO (Doelsch et al., 2003).

Iron oxyhydroxides are one of the most pervasive products of alteration and oxidation of deep-sea hydrothermal fluids and solids alike. Our results provide insight into the structure and formation of naturally occurring, microbiologically produced $\mathrm{Fe}$ oxyhydroxide minerals in the deepsea. Microbial activity has been implicated, but in most cases has not been linked concretely to mineral weathering and formation in the deep-sea. Definitively linking microbial activity to mineral by-products is difficult, but has been accomplished here through integration of multiple, spatially resolved approaches that access different mineralogical properties of the material at different spatial scales.

Our use of a polyhedral approach for the identification of $\mathrm{Fe}$ oxyhydroxide structural properties takes advantage of more than a decade's worth of laboratory experimentation and X-ray absorption spectroscopic measurements on 
the oxidation, hydrolysis, and polymerization of $\mathrm{Fe}$ (see Table 3). The exact structure or continuum of structures possessed by ferrihydrite is an active topic of research and scientific discourse (Michel et al., 2007; Manceau, 2008). In this contribution, we have placed the seafloor-formed BIO within a local-structure continuum and have discovered that the BIO has less three-dimensional character than laboratory synthesized ferrihydrite reference minerals. We consider this seafloor-formed, Fe-encrusted biofilm of known age to be a mineralogical starting point for future studies of seafloor sulfide-weathering processes. In essence, this study represents a time-zero for microbial weathering processes for which a morphological and mineralogical signal is produced. Our future efforts will be directed at examining progressively older and more extensively weathered seafloor sulfide minerals, with the aim of better interpreting ancient microbial processes and the preservation of the biological signatures associated with those processes.

\section{ACKNOWLEDGMENTS}

B.M.T.'s research was funded by a NASA Astrobiology Institute, National Research Council/NASA Postdoctoral Program fellowship. Project funding was supplied by NSF RIDGE2000 Grants OCE-0096992 (to K.J.E.) and OCE-0241791 (to K.J.E. and W.B.), and a NASA NAI Grant (to K.J.E.). We thank Jeffery Seewald for the opportunity to participate on a cruise to deploy the samples and Margaret Tivey for sample recovery. We thank Sirine Fakra and Nobumichi Tamura for help with data collection on BLs 10.3.2 and 7.3.3, and David Emerson for discussions regarding the manuscript. Research conducted on at the Advanced Light Source at Lawrence Berkeley National Laboratory is supported by the Office of Science, Basic Energy Sciences, and Division of Materials Science of the U.S. Department of Energy under contract number DE-AC02-05CH11232.

\section{APPENDIX A. SUPPLEMENTARY DATA}

Supplementary data associated with this article can be found, in the online version, at doi:10.1016/ j.gca.2008.09.035.

\section{REFERENCES}

Bach W., J E. K., Hayes J. M., Huber J. A., Sievert S. M. and Sogin M. L. (2006) Energy in the dark: Fuel for life in the deep ocean and beyond. EOS 87, 73-78.

Banfield J. F., Welch S. A., Zhang H., Thomsen T. and Penn R. L. (2000) Aggregation-based crystal growth and microstructure development in natural iron oxyhydroxide biomineralization products. Science $\mathbf{2 8 9}, \mathbf{7 5 1 - 7 5 4 .}$

Benzerara K., Menguy N., Guyot F., Vanni C. and Gillet P. (2005) TEM study of a silicate-carbonate-microbe interface prepared by focused ion beam milling. Geochim. Cosmochim. Acta 69, $1413-1422$.

Blumenberg M., Seifert R., Petersen S. and Michaelis W. (2007) Biosignatures present in a hydrothermal massive sulfide from the Mid-Atlantic Ridge. Geobiology 5, 435-450.

Chan C. S., Stasio G. D., Welch S. A., Girasole M., Frazer B. H., Nesterova M. V., Fakra S. and Banfield J. F. (2004) Microbial polysaccharides template assembly of nanocrystal fibers. Science 303, 1656-1658.
Chatellier X., West M. M., Rose J., Fortin D., Leppard G. G. and Ferris F. G. (2004) Characterization of iron-oxides formed by oxidation of ferrous ions in the presence of various bacterial species and inorganic ligands. Geomicrobiol. J. 21, 99-112.

Combes J. M., Manceau A., Calais G. and Bottero J. Y. (1989) Formation of ferric oxides from aqueous solutions: a polyhedral approach by X-ray absorption spectroscopy: I. Hydrolysis and formation of ferric gels. Geochim. Cosmochim. Acta 53, 583-594.

Cornell R. M. and Schwertmann U. (1979) Influence of organic anions on the crystallization of ferrihydrite. Clays Clay Mineral. 27, 402-410.

Doelsch E., Masion A., Rose J., Stone W. E. E., Bottero J. Y. and Bertsch P. M. (2003) Chemistry and structure of colloids obtained by hydrolysis of $\mathrm{Fe}(\mathrm{III})$ in the presence of $\mathrm{SiO}_{4}$ ligands. Colloids Surfaces A: Physicochem. Eng. Aspects 217, $121-128$.

Druschel G. K., Emerson D., Sutka R., Suchecki P. and Luther, III, G. W. (2008) Low-oxygen and chemical kinetic constraints on the geochemical niche of neutrophilic iron(II) oxidizing microorganisms. Geochim. Cosmochim. Acta 72, 3358-3370.

Edwards K. J., Bach W. and McCollom T. M. (2005) Geomicrobiology in oceanography: microbe-mineral interactions at and below the seafloor. Trends Microbiol. 13, 449-456.

Edwards K. J., Bach W., McCollom T. M. and Rogers D. R. (2004) Neutrophilic iron-oxidizing bacteria in the ocean: their habitats, diversity, and roles in mineral deposition, rock alteration, and biomass production in the deep-sea. Geomicrobiol. J. 21, 393 404.

Edwards K. J., McCollom T. M., Konishi H. and Buseck P. R. (2003a) Seafloor bioalteration of sulfide minerals: results from in situ incubation studies. Geochim. Cosmochim. Acta 67, 28432856.

Edwards K. J., Rogers D. R., Wirsen C. O. and McCollom T. M. (2003b) Isolation and characterization of novel psychrophilic, neutrophilic, Fe-oxidizing, chemolithoautotrophic $\alpha$ - and $\gamma$ Proteobacteria from the Deep Sea. Appl. Environ. Microbiol. 69, 2906-2913.

Emerson D. and Moyer C. L. (2002) Neutrophilic Fe-oxidizing bacteria are abundant at the Loihi seamount hydrothermal vents and play a major role in $\mathrm{Fe}$ oxide deposition. Appl. Environ. Microbiol. 68, 3085-3093.

Emerson D., Rentz J. A., Lilburn T. G., Davis R. E., Aldrich H., Chan C. S. and Moyer C. L. (2007) A novel lineage of proteobacteria involved in formation of marine Fe-oxidizing microbial mat communities. PLoS One 2, e667.

Feely R. A., Lewison M., Massoth G. J., Rober-Baldo G., Lavelle J. W., Byrne R. H., Damm K. L. V. and HC Curl J. (1987) Composition and dissolution of black smoker particulates from active vents on the Juan de Fuca Ridge. J. Geophys. Res. 92, 11347-11363.

Field M. P. and Sherrell R. M. (2000) Dissolved and particulate Fe in a hydrothermal plume at $9^{\circ} 45^{\prime} \mathrm{N}$, East Pacific Rise: slow $\mathrm{Fe}(\mathrm{II})$ oxidation kinetics in Pacific plumes. Geochim. Cosmochim. Acta 64, 619-628.

German C. R. and von Damm K. L. (2004) Hydrothermal processes. Treatise Geochem. 6, 181-222.

Glynn S., Mills R. A., Palmer M. R., Pancost R. D., Severmann S. and Boyce A. J. (2006) The role of prokaryotes in supergene alteration of submarine hydrothermal sulfides. Earth Planet. Sci. Lett. 244, 170-188.

Gualtieri A. F. and Venturelli P. (1999) In situ study of the goethite-hematite phase transformation by real time synchrotron powder diffraction. Am. Mineral. 84, 895-904. 
Hallbeck L., Stahl F. and Pedersen K. (1993) Phylogeny and phenotypic characterization of the stalk-forming and ironoxidizing bacterium Gallionella ferruginea. J. Gen. Microbiol. 139, 1531-1535.

Hansel C. M., Benner S. G., Neiss J., Dohnalkova A., Kukkadapu R. K. and Fendorf S. (2003) Secondary mineralization pathways induced by dissimilatory iron reduction of ferrihydrite under advective flow. Geochim. Cosmochim. Acta 67, 29772992.

Hofmann B. A., Farmer J. D., Von Blanckenburg F. and Fallick A. E. (2008) Subsurface filamentous fabrics: an evaluation of origins based on morphological and geochemical criteria, with implications for Exoplanetology. Astrobiology 8, 87-117.

Huber J. A., Welch D. M., Morrison H. G., Huse S. M., Neal P. R., Butterfield D. A. and Sogin M. L. (2007) Microbial population structures in the deep marine biosphere. Science 318, 97-100.

Jambor J. L. and Dutrizac J. E. (1998) Occurrence and constitution of natural and synthetic ferrihydrite, a widespread iron oxyhydroxide. Chem. Rev. 98, 2549-2585.

Janney D. E., Cowley J. M. and Buseck P. R. (2000) Structure of synthetic 2-line ferrihydrite by electron nanodiffraction. Am. Mineral. 85, 1180-1187.

Janzen M. P., Nicholson R. V. and Scharer J. M. (2000) Pyrrhotite reaction kinetics: Reaction rates for oxidation by oxygen, ferric iron, and for nonoxidative dissolution. Geochim. Cosmochim. Acta 64, 1511-1522.

Karl D. M., Wirsen C. O. and Jannasch H. W. (1980) Deep-sea primary production at Galapagos hydrothermal vents. Science 207, 1345-1347.

Kormas K. A., Tivey M. K., von Damm K. L. and Teske A. (2006) Bacterial and archaeal phylotypes associated with distinct mineralogical layers of a white smoker spire from a deep-sea hydrothermal vent site $\left(9^{\circ} \mathrm{N}\right.$, East Pacific Rise). Environ. Microbiol. 8, 909-920.

Koski R. A., Shanks, III, W. C., Bohrson W. A. and Oscarson R. L. (1988) The composition of massive sulfide deposits from the sediment-covered floor of Escanaba Trough, Gorda Ridge: implications for depositional processes. Can. Mineral. 26, 655673.

Lawrence J. R., Kwong Y. T. J. and Swerhone G. D. W. (1997) Colonization and weathering of natural sulfide assemblages by Thiobacillus ferrooxidans. Can. J. Microbiol. 43, 178-188.

Lee M. R., Brown D. J., Smith C. L., Hodson M. E., MacKenzie M. and Hellmann R. (2007) Characterization of mineral surfaces using FIB and TEM: a case study of naturally weathered alkali feldspars. Am. Mineral. 92, 13831394.

Luther, III, G. W., Kostka J. E., Church T. M., Sulzberger B. and Stumm W. (1992) Seasonal iron cycling in the salt-marsh sedimentary environment: the importance of ligand complexes with $\mathrm{Fe}(\mathrm{II})$ and $\mathrm{Fe}(\mathrm{III})$ in the dissolution of $\mathrm{Fe}(\mathrm{III})$ minerals and pyrite, respectively. Marine Chem. 40, 81-103.

Manceau A. (accepted for publication) Evaluation of the structural model for ferrihydrite derived from real-space modeling of high-energy X-ray diffraction data. Clay Minerals.

Manceau A. and Combes J. M. (1988) Structure of Mn and Fe oxides and oxyhydroxides: a topological approach by EXAFS. Phys. Chem. Minerals 15, 283-295.

Manceau A. and Drits V. A. (1993) Local structure of ferrihydrite and feroxyhite by EXAFS spectroscopy. Clay Minerals 28, 165184.

Manceau A., Marcus M. A. and Tamura N. (2002) Quantitative speciation of heavy metals in soils and sediments by synchrotron X-ray techniques. In Applications of Synchrotron Radiation in low-Temperature Geochemistry and Environmental Science (eds. P. A. Fenter, M. L. Rivers, N. C. Sturchio and S. R. Sutton). Mineralogical Society of America, Washington, DC.

Marcus M. A., MacDowell A., Celestre R., Manceau A., Miller T., Padmore H. A. and Sublett R. E. (2004) Beamline 10.3.2 at ALS: a hard X-ray microprobe for environmental and material sciences. J. Synchrotron Rad. 11, 239-247.

Masion A., Doelsch E., Rose J., Moustier S., Bottero J. Y. and Bertsch P. M. (2001) Speciation and crystal chemistry of iron(III) chloride hydrolyzed in the presence of $\mathrm{SiO}_{4}$ ligands. 3 . Semilocal scale structure of the aggregates. Langmuir 17, 4753 4757.

McCollom T. M. (2000) Geochemical constraints on primary productivity in submarine hydrothermal vent plumes. Deep-Sea Res. 47, 85-101.

McCollom T. M. and Shock E. L. (1997) Geochemical constraints on chemolithoautotrophic metabolism by microorganisms in seafloor hydrothermal systems. Geochim. Cosmochim. Acta 61, 4375-4391.

Michel F. M., Ehm L., Antao S. M., Lee P. L., Chupas P. J., Liu G., Strongin D. R., Schoonen M. A. A., Phillips B. L. and Parise J. B. (2007) The structure of ferrihydrite, a nanocrystalline material. Science 316, 1726-1729.

Mikhlin Y. and Tomashevich Y. (2005) Pristine and reacted surfaces of pyrrhotite and arsenopyrite as studied by X-ray absorption near-edge structure spectroscopy. Phys. Chem. Minerals 32, 19-27.

Moreau J. W., Weber P. K., Martin M. C., Gilbert B., Hutcheon I. D. and Banfield J. F. (2007) Extracellular proteins limit the dispersal of biogenic nanoparticles. Science 316, 1600-1603.

Nercessian O., Fouquet Y., Pierre C., Prieur D. and Jeanthon C. (2005) Diversity of bacteria and archaea associated with a carbonate-rich metalliferous sediment sample from the Rainbow vent field on the Mid-Atlantic Ridge. Environ. Microbiol. 7, 608-714.

Newville M. (2001) IFEFFIT: interactive XAFS analysis and FEFF fitting. J. Synchrotron Rad. 8, 324-332.

Nordstrom D. K. and Alpers C. N. (1999) Geochemistry of acid mine waters. In The Environmental Geochemistry of Mineral Deposits: Part A. Processes, Methods, and Health Issues (eds. G. S. Plumee and M. D. Logston). Society of Economic Geologists, Littleton, CO.

O'Day P. A., Rivera, Jr., N., Root R. and Carroll S. A. (2004) Xray absorption spectroscopic study of Fe reference compounds for the analysis of natural sediments. Am. Mineral. 89, 572-585.

Obst M., Gasser P., Mavrocordatos D. and Dittrich M. (2005) TEM-specimen preparation of cell/mineral interfaces by Focused Ion Beam milling. Am. Mineral. 90, 1270-1277.

Perner M., Kuever J., Seifert R., Pape T., Koschinsky A., Schmidt K., Strauss H. and Imhoff J. F. (2007) The influence of ultramafic rocks on microbial communities at the Logatchev hydrothermal field, located $15^{\circ} \mathrm{N}$ on the Mid-Atlantic Ridge. FEMS Microbiol. Ecol. 61, 97-109.

Ravel B. (1999) TkAtoms version 3.0 beta 9.

Ravel B. (2000) EXAFS analysis using FEFF and FEFFIT. A workshop with course materials available on CD-ROM at http://feff.Phys.washington.edu/ravel/course/.

Rehr J. J., Zabinsky S. I. and Albers R. C. (1992) High-order multiple-scattering calculations of $\mathrm{x}$-ray absorption fine structure. Phys. Rev. Lett. 69, 3397-3400.

Rentz J. A., Kraiya C., Luther, I, G. W. and Emerson D. (2007) Control of ferrous iron oxidation within circumneutral microbial iron mats by cellular activity and autocatalysis. Environ. Sci. Technol. 41, 6084-6089.

Roden E. E., Sobolev D., Glazer B. and Luther, III, G. W. (2004) Potential for microscale bacterial $\mathrm{Fe}$ redox cycling at the aerobic-anaerobic interface. Geomicrobiol. J. 21, 379-391. 
Rogers D. R., Santelli C. M. and Edwards K. J. (2003) Geomicrobiology of deep-sea deposits: estimating community diversity from low-temperature seafloor rocks and minerals. Geobiology 1, 109-117.

Rose J., Flank A.-M., Masion A., Bottero J. Y. and Elmerich P. (1997) Nucleation and growth mechanisms of Fe oxyhydroxide in the presence of $\mathrm{PO}_{4}$ ions. 2. $\mathrm{P}$ K-edge EXAFS study. Langmuir 13, 1827-1834.

Rose J., Manceau A., Bottero J. Y., Masion A. and Garcia F. (1996) Nucleation and growth mechanisms of Fe oxyhydroxide in the presence of PO4 ions. 1. Fe K-edge EXAFS study. Langmuir 12, 6701-6707.

Schrenk M. O., Kelley D. S., Delaney J. R. and Baross J. A. (2003) Incidence and diversity of microorganisms within the walls of an active deep-sea sulfide chimney. Appl. Environ. Microbiol. 69, 3580-3592.

Schwertmann U., Friedl J. and Kyek A. (2004) Formation and properties of a continuous crystallinity series of synthetic ferrihydrites (2- to 6-line) and their relation to $\mathrm{FeOOH}$ forms. Clays Clay Mineral. 52, 221-226.

Suzuki Y., Inagaki K., Takai K., Nealson K. H. and Horikoshi K. (2004) Microbial diversity in inactive chimney structures from deep-sea hydrothermal systems. Microbial. Ecol. 47, 186-196.

Tamura N., Celestre R. S., MacDowell A. A., Padmore H. A., Spolenak R., Valek B. C., Chang N. M., Manceau A. and Patel J. R. (2002) Submicron X-ray diffraction and its application to problems in materials and environmental science. Rev. Sci. Instrum. 73, 1369-1372.

Teske A., Hinrichs K.-U., Edgcomb V., a Gomez A., Kysela D., Sylva S. P., Sogin M. L. and Jannasch H. W. (2002) Microbial diversity of hydrothermal sediments in the Guaymas Basin: evidence for anaerobic methanotrophic communities. Appl. Environ. Microbiol. 68, 1994-2007.

Tivey M. K. (1995) The influence of hydrothermal fluid composition and advection rates on black smoker chimney mineralogy: insights from modeling transport and reaction. Geochim. Cosmochim. Acta 59, 1933-1949.

Vilge-Ritter A., Rose J., Masion A., Bottero J. Y. and Laine J. M. (1999) Chemistry and structure of aggregates formed with Fesalts and natural organic matter. Coll Surfaces A: Physicochem. Eng. Aspects 147, 297-308.

Waychunas G., Fuller C. and Davis J. (2002) Surface complexation and precipitate geometry for aqueous $\mathrm{Zn}$ (II) sorption on ferrihydrite I: X-ray absorption extended fine structure spectroscopy analysis. Geochim. Cosmochim. Acta 66, 11191137.

Waychunas G. A., Fuller C. C., Rea B. A. and Davis J. A. (1996) Wide angle X-ray scattering (WAXS) study of "two-line" ferrihydrite structure: Effect of arsenate sorption and counterion variation and comparison with EXAFS results. Geochim. Cosmochim. Acta 60, 1765-1781.

Webb S. M. (2005) SIXPACK: a graphical user interface for XAS analysis using IFEFFIT. Phys. Scripta T115, 10111014.

Wirth R. (2004) Focused ion beam (FIB): a novel technology for advanced application of micro- and nanoanalysis in geosciences and applied mineralogy. Eur. J. Mineral. 16, 863-876.

Associate editor: Liane G. Benning 